\title{
Small Gold Nanorods: Recent Advances in Synthesis, Biological Imaging, and Cancer Therapy
}

\author{
Lu An, Yuanyuan Wang, Qiwei Tian * and Shiping Yang *
}

The Key Laboratory of Resource Chemistry of the Ministry of Education, the Shanghai Key Laboratory of Rare Earth Functional Materials, and the Shanghai Municipal Education Committee Key Laboratory of Molecular Imaging Probes and Sensors, Shanghai Normal University, Shanghai 200234, China; anlu1987@shnu.edu.cn (L.A.); 1000398653@smail.shnu.edu.cn (Y.W.)

* Correspondence: qiweitian@shnu.edu.cn (Q.T.); shipingy@shnu.edu.cn (S.Y.); Tel.: +86-021-6432-2343 (Q.T. \& S.Y.)

Received: 20 October 2017; Accepted: 25 November 2017; Published: 30 November 2017

\begin{abstract}
Over the past few decades, the synthetic development of ultra-small nanoparticles has become an important strategy in nano-medicine, where smaller-sized nanoparticles are known to be more easily excreted from the body, greatly reducing the risk caused by introducing nano-theranostic agents. Gold nanorods are one of the most important nano-theranostic agents because of their special optical and electronic properties. However, the large size (diameter $>6 \mathrm{~nm}$ ) of most obtained gold nanorods limits their clinical application. In recent years, more and more researchers have begun to investigate the synthesis and application of small gold nanorods (diameter $<6 \mathrm{~nm}$ ), which exhibit similar optical and electronic properties as larger gold nanorods. In this review, we summarize the recent advances of synthesis of the small gold nanorods and their application for near-infrared light-mediated bio-imaging and cancer therapy.
\end{abstract}

Keywords: small gold nanorods; seedless; biological imaging; cancer therapy

\section{Introduction}

In recent years, near-infrared light-mediated multifunctional platforms based on inorganic nanomaterials for cancer diagnosis and treatment have been explored widely [1-3], including carbon [4-6], semiconductors [7-9], and noble metals [10-13]. Gold nanomaterials [10,11,14], especially gold nanorods [15-17], attract more attention. Several intrinsic physicochemical properties make gold nanorods a promising multifunctional platform for cancer theranostics. First, the strong surface plasma resonance (SPR) absorption of the gold nanorods enables them to absorb more light even with tiny amounts of gold nanorods $[18,19]$. Secondly, the SPR absorption of the gold nanorods can be easily tuned to the near-infrared (NIR) window $(650-1350 \mathrm{~nm})[20,21]$ where light can penetrate more deeply because of scarce absorption by tissues and blood [22]. Lastly, the gold nanorods can be more easily modified by the thiol compounds via strong Au-S bonds, formed by the thiol group and the surface of gold nanorods [23]. Thus, the design of multifunctional theranostic platforms based on gold nanorods becomes very easy by adding the targeting or imaging agents onto the gold nanorods' surface [24,25]. These facts—strong absorption, deep penetration, and easy modular functionality-show gold nanorods to be an attractive NIR light-mediated multifunctional platform for cancer theranostics [26-28].

Great efforts have been made by the researchers to synthesize the high quality and yield gold nanorods with tunable SPR absorption to investigate the great potential for cancer theranostics [15,29]. However, the commonly synthesized gold nanorods have a scattering cross-section, which is comparable to their absorption cross-section, and which will reduce the photothermal conversion efficiency [30]. On the other hand, these gold nanorods will accumulate in the reticuloendothelial system (RES) organs and tissues rapidly after intravenous injection due to their relatively large size 
(a width greater than $8 \mathrm{~nm}$ and a length of about $40 \mathrm{~nm}$ ) [31]. Thus, the large-sized gold nanorods cannot be cleared out from the body in a timely manner, causing potential long-term toxicity [32]. Additionally, it is difficult to meet the requirements of the U.S. Food and Drug Administration (FDA), limiting their clinical translation. All these facts will limit the application of large-sized gold nanorods in near-infrared light-mediated bio-imaging and cancer therapy. Fortunately, it was found that the absorption-to-scattering ratio of gold nanorods increases with a decrease in diameter, and gold nanorods with diameters smaller than $10 \mathrm{~nm}$ were dominated by absorption, which could minimize the impact of the scattering cross-section [33]. Therefore, small gold nanorods (diameter $<6 \mathrm{~nm}$ ) which can be quickly excreted from the body need to be developed urgently [34,35].

In order to obtain the small gold nanorods, several different methods have been developed, mainly including the seed-mediated method and seedless method [36,37]. For example, high quality small gold nanorods have been obtained by Wang's group using the seed-mediated method by changing the seed-to- $\mathrm{Au}(\mathrm{III})$ molar ratio in the growth solution [38], while ultra-small size gold nanorods were synthesized by El-Sayed et al. using the seedless method by adjusting the $\mathrm{pH}$ and $\mathrm{NaBH}_{4}$ concentrations [39]. Due to the excellent properties of the small gold nanorods, including strong absorption, low toxicity and rapid clearance from body, the small size gold nanorods are recently widely used for bio-applications, including photoacoustic imaging, photothermal therapy, and so on. Thus, it is important to review the development of small gold nanorods for the further extending its application.

In this review, we first summarize the recent progress on the synthesis of the small gold nanorods with three different methods. Then, the SPR absorption properties and the surface modification of small gold nanorods were mainly discussed. Finally, we highlight the recent advances of small gold nanorods for a NIR light-mediated multifunctional theranostic platforms, including bio-imaging and cancer therapy.

\section{Synthesis of Small Gold Nanorods}

The synthesis of monodispersed small gold nanorods has attracted much attention for their optical properties and biomedical applications. Many methods have been developed for the synthesis of monodispersed small gold nanorods with different aspect ratios, including the seed-mediated method, the seedless method, and the high-temperature seedless method.

\subsection{Seed-Mediated Method}

The seed mediated method is the typical and more commonly used method for preparing gold nanorods due to the high quality and yield of nanorods, and their tunable size. Generally, two steps are included for the seed-mediated method: the first step is to prepare a small-sized gold seed; the second step is the growth of gold nanorods, which is initiated by the gold seed in the growth solution. The size, aspect ratios, and yield can be tuned by controlling the size of the seed, seed amount, and reaction parameters in the growth solution, including surfactant amount, gold precursor concentration, $\mathrm{pH}$ value, and so on.

The seed-mediated growth method was originated in 2001 by Jana et al. [36]. First, the citrate-capped gold seed and growth solution which contained cetyltrimethyl ammonium bromide (CTAB), acetone, hexane, and water, were prepared separately. Then, the growth of the gold nanorods was started by adding the freshly-prepared ascorbic acid to the mixture of gold seed and growth solution in the presence of $\mathrm{AgNO}_{3}$. However, the yield of gold nanorods for Jana's method is very low, and more spherical particles are produced. In 2003, El-Sayed et al. [39] improved Jana's method by two modifications. One uses the stronger CTAB stabilizer to cap the gold seed; the other introduced silver nitrate to the gold solution before seed addition to facilitate the rod formation and also tune the aspect ratio. For the developed method, the yield of the gold nanorods is about $99 \%$ and the aspect ratios can be tuned from 1.5 to 4.5 .

The seed-mediated method is a typical synthesized method for large size gold nanorods, but it is not very good for Au nanorods smaller than $6 \mathrm{~nm}$. Until now, only several reports use the seed-mediated method to synthesize the small gold nanorods. Murphy's group [40,41] developed 
a simple millifluidic reactor which can synthesize the small gold nanorods (diameter ca. $6.6 \mathrm{~nm}$ ) at the gram-scale, based on the seed-mediated method, but the yield of nanorods and size uniformity are difficult to control. Wang's group [38] obtained the best quality of small gold nanorods using the seed-mediated method by changing the seed-to-Au(III) molar ratio in the growth solution (Figure 1). They are named GmSn, G, and S, referring to the growth solution and the seed solution, respectively; $\mathrm{m}$ is the volume of the surfactant solution used in preparing the growth solution, and $\mathrm{n}$ is the volume of the seed solution. CTAB or cetyltripropylammonium bromide (CTPAB) was employed as the stabilizing surfactant in the growth solution. They demonstrate that the molar ratio of the seed-to-Au(III) plays an important effect on the size. When the seed concentration increased in a given growth solution, the size of the obtained gold nanorods will decrease. However, it is difficult to obtain diameters less than $6 \mathrm{~nm}$ by this method.
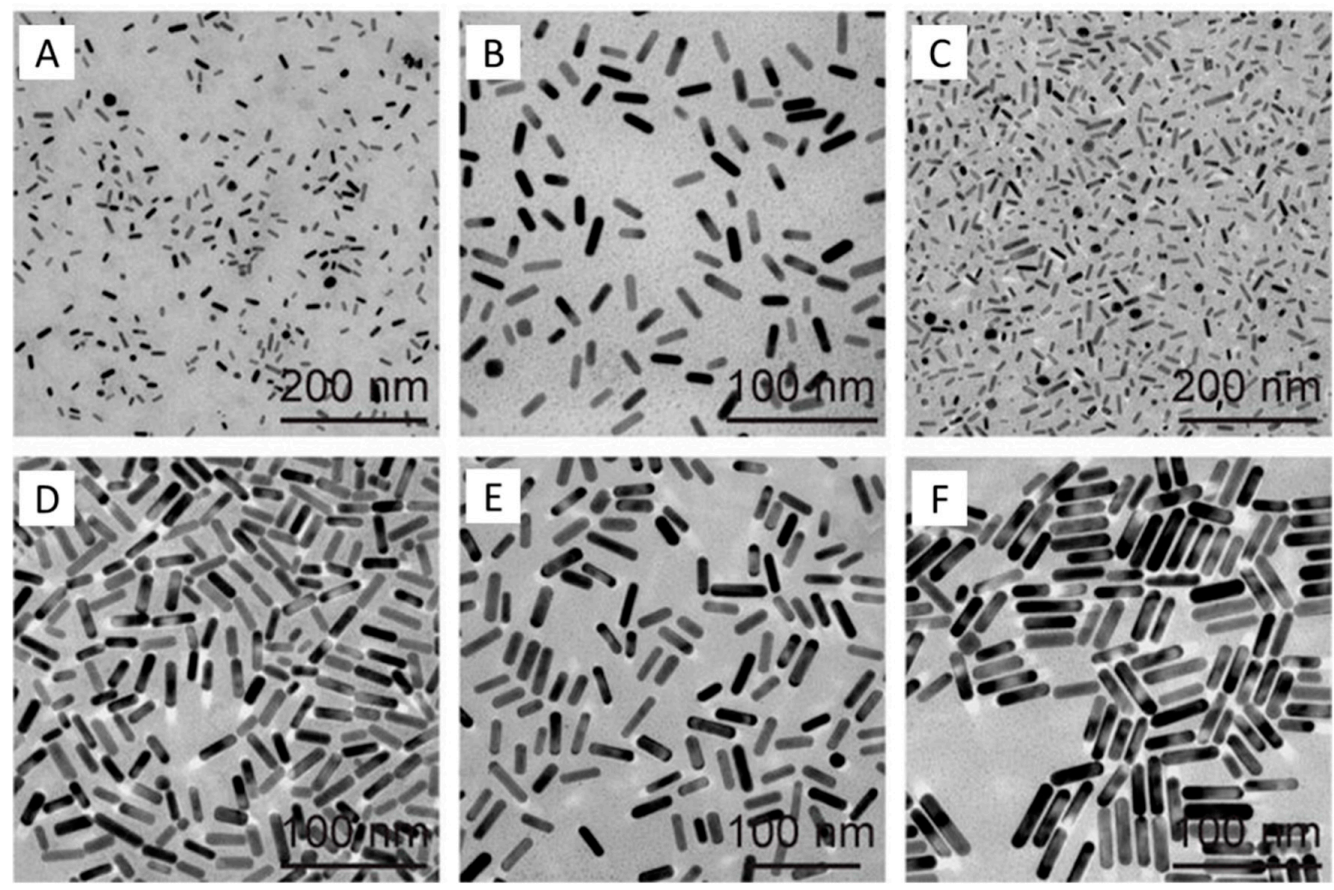

Figure 1. Transmission electron microscopy (TEM) images of the small Au nanorods samples (GmSn) obtained with different molar ratio of seed-to-Au(III) in the growth solution. (A-C) G1S9, G2S8, and G4S6 were grown with cetyltripropylammonium bromide (CTPAB), and (D-F) G6S4, G8S2, and G9S1 were grown with CTAB [38].

\subsection{Seedless Method}

Recently, the two-step seed growth method has been simplified as a seedless growth method, and is used for the preparation of small-sized gold nanorods (diameter $<5 \mathrm{~nm}$ ), which is difficult to obtained by the seed-mediated method [42]. For the seedless growth method, no seed preparation step is required for growth of the small-sized gold nanorods, due to nucleation and growth occurring in the same solution. The seed for the growth of the gold nanorods is generated by adding $\mathrm{NaBH}_{4}$ directly to the growth solution, which is well known as the strong reducing agent that can reduce $\mathrm{Au}^{3+}$ to $\mathrm{Au}^{0}$. The small gold nanoparticles formed by adding $\mathrm{NaBH}_{4}$ can play the role of seeds to prepare the gold nanorods [43,44]. By this seedless method, the ultra-small gold nanorods (diameter $<5 \mathrm{~nm}$ ) will be easily obtained because the directly-formed seed is small enough in the growth solution [37].

The seedless method was discovered by Jana et al. firstly (Figure 2A) [42]. In the CTAB micellar solution of the $\mathrm{HAuCl}_{4}$, the strong $\left(\mathrm{NaBH}_{4}\right)$ and weak (ascorbic acid) reducing agents were introduced, in which the CTAB micelle was the template for nanorod growth, strong reducing agent was used to generate the seed in the growth solution directly and the weak reducing agent helped the nanoparticles 
to grow. They found that if the nucleation kinetics of nanoparticle formation are properly adjusted, the elongated rod-like micelle surface can be a useful template, and the resulting nanoparticles would be highly anisotropic and near-monodisperse. However, the nucleation kinetics of nanoparticle formation is difficult to control and the preparation process is accompanied by a large number of spherical gold nanoparticles, resulting in a low yield of gold nanorods. El-Sayed et al. [37] further developed the seedless method (Figure 2B). They found that the $\mathrm{pH}$ plays a crucial role in the monodispersity of the nanorods when the $\mathrm{NaBH}_{4}$ concentration of the growth solution was adjusted to control the reduction rate of the gold ions. The reducing power of ascorbic acid and $\mathrm{NaBH}_{4}$ decreases with decreasing $\mathrm{pH}$, and the homogeneity of the small gold nanorods increased. At the optimized $\mathrm{pH}$ and $\mathrm{NaBH}_{4}$ concentrations, smaller gold nanorods were produced by adjusting the $\mathrm{CTAB}$ concentration in the growth solution. The higher concentration of CTAB in the growth solution stabilized initial single crystalline nuclei and decreased the growth of rods more than usual, so the gold nanorods were smaller compared to those prepared at a lower CTAB concentration. In addition, the concentration of silver ions in the growth solution was found to be pivotal in controlling the aspect ratio of the nanorods. The aspect ratio decreases as the silver ions concentration decreases. By this new method, it is easier to prepare higher yield, high quality, and ultra-small gold nanorods.
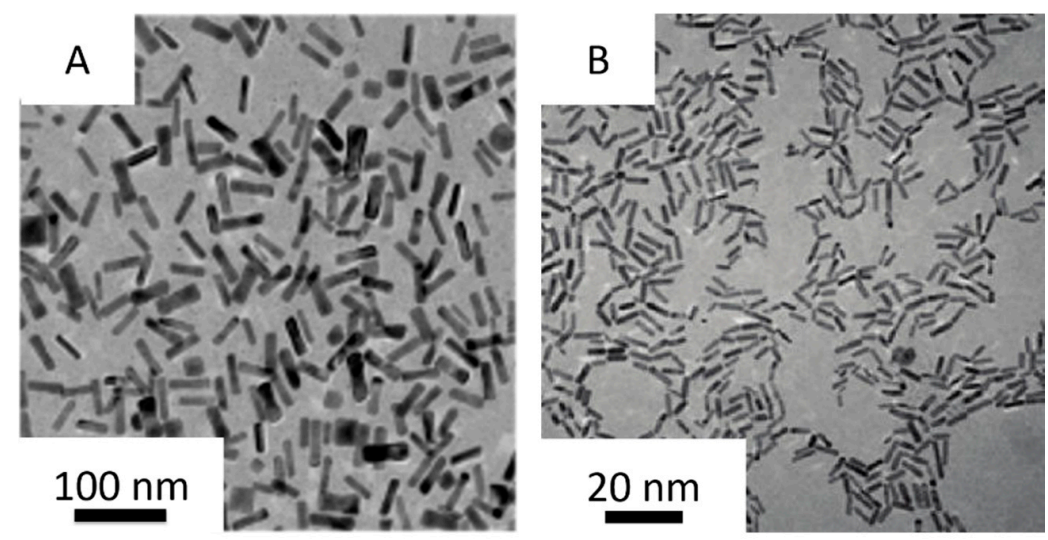

Figure 2. Typical TEM images of the small gold nanorods obtained by Jana et al. [42] ((A) $1 \mathrm{mM}$ $\mathrm{HAuCl}_{4}, 0.2 \mathrm{M} \mathrm{CTAB}, 0.2 \mathrm{mM} \mathrm{AgNO} 3,2 \mathrm{mM}$ ascorbic acid, $0.25 \mu \mathrm{M} \mathrm{BH}_{4}$ ), and El-Sayed et al. [37] ((B) $5.0 \mathrm{~mL} \mathrm{HAuCl}_{4}, 5.0 \mathrm{~mL} \mathrm{CTAB}, 270 \mu \mathrm{L} \mathrm{AgNO}_{3}, 8 \mu \mathrm{L} \mathrm{HCl}, 70 \mu \mathrm{L}$ ascorbic acid, $15 \mu \mathrm{L} \mathrm{NaBH}_{4}$ ).

\subsection{High-Temperature Seedless Method}

Many groups have reported methods for synthesizing gold nanorods at room temperature. Perez-Juste et al. [45] indicated that reaction temperatures close to room temperature are more beneficial for higher nanorod yields. However, Zijlstra et al. [44] synthesized gold nanorods at temperatures varying between 25 and $97{ }^{\circ} \mathrm{C}$, and presented a kinetics study of seedless nanorod synthesis at high temperatures (Figure 3). They found a decrease in rod length when the temperature was gradually raised to $97^{\circ} \mathrm{C}$. It demonstrates that three orders of magnitude increase in the growth rate for $\mathrm{Au}$ nanorods synthesized at $97^{\circ} \mathrm{C}$ and an average activation energy for growth on all facets to be $90 \pm 10 \mathrm{~kJ} \mathrm{~mol}^{-1}$. High-temperature gold nanorod synthesis opens the door to resolving two important issues which have not been addressed in the literature so far. First, ultrafast high-temperature synthesis presents a better system for rapid production of gold nanorods for potential commercial applications. Second, the fact that gold nanorods form at high temperatures suggests that using a thermally-activated reducing agent is possible. Most reports on gold nanorod synthesis utilize $\mathrm{NaBH}_{4}$ to initiate the formation of gold nanorods [39]. $\mathrm{NaBH}_{4}$ reacts with water and has to be used immediately after preparation, which compromises reproducibility. Using a thermally-activated reducing agent would avoid the use of the unstable $\mathrm{NaBH}_{4}$, resulting in stock growth solutions that are stable at room temperature. 

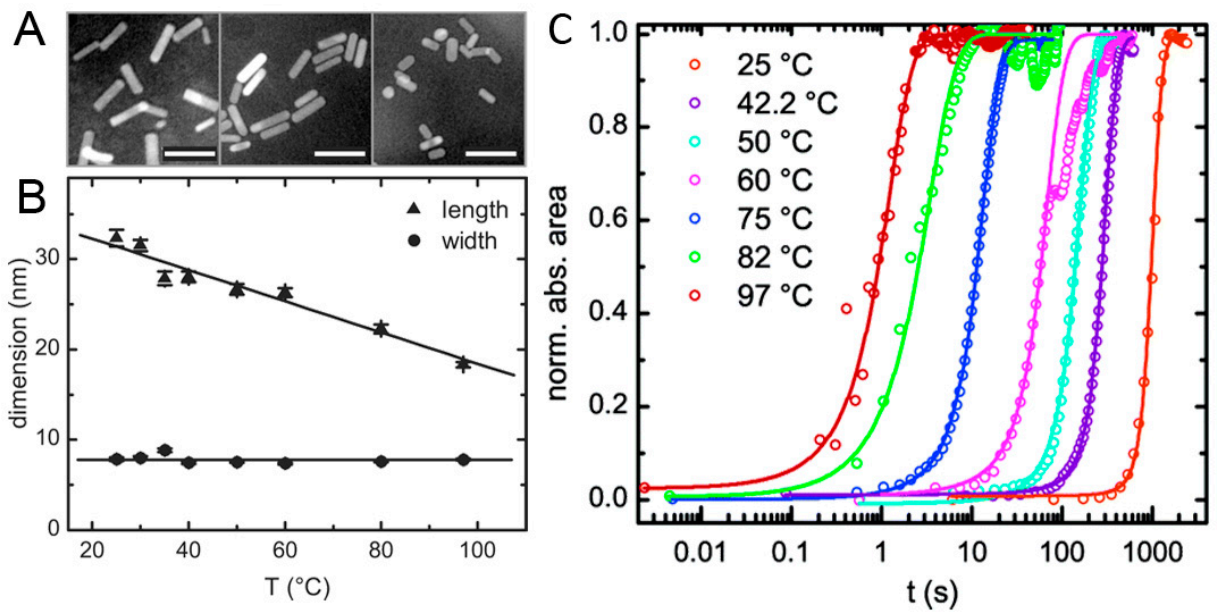

Figure 3. (A) TEM images obtained from gold nanorods synthesized at $25^{\circ} \mathrm{C}, 50^{\circ} \mathrm{C}$, and $97^{\circ} \mathrm{C}$ from left to right. The scale bars indicate $50 \mathrm{~nm}$. (B) Particle dimension as obtained from TEM analysis. The error bars represent the error in the mean value of the distribution of the respective dimension. (C) Evolution of the integrated absorbance vs. time for nanorods synthesized at different temperatures. The solid lines are sigmoidal fits to the experimental data points [44].

\section{Surface Modification of Small Gold Nanorods}

Even though $C T A B$ is an almost necessary surfactant for the synthesis of the gold nanorods, the high cytotoxity of CTAB limited its application in biochemistry and biomedicine [46]. Thus, the CTAB must be removed from the surface of the gold nanorods before it is used for bio-applications. Until now, several strategies have been investigated for solving these problems [18,47-52]. Among of them, coating organic or inorganic materials on Au nanorods and replacing the CTAB by thiol-terminated molecules have been proven to be the most effective approaches for improving their biocompatibility.

\subsection{Surface Coating Method}

For the surface coating method, $\mathrm{SiO}_{2}$ or polymers (e.g., bovine serum albumin) were normally used to directly coat on the surface of gold nanorods. Due to the effective and high hardness of $\mathrm{SiO}_{2}$ coating, the gold nanorods coated with $\mathrm{SiO}_{2}$ can not only reduce the toxic effect, but also prevent them from aggregating. In addition, the pores are generated in the $\mathrm{SiO}_{2}$ coating, and the $\mathrm{SiO}_{2}$-coated gold nanorods can also be used for drug delivery [47]. Bovine serum albumin (BSA) is one kind of low cost biomacromolecules and is widely used for biomedicine. In order to improve the biocompatibility of the gold nanorods, BSA has also been used to coat the surface of the gold nanorods. Due to strong thiol binding sites on the BSA, the gold nanorods are easily been coated by the BSA when they mix together. It was easily demonstrated if the BSA was coated on the gold nanorods by the extinction spectra, the absorption maxima of the gold nanorods showed a distinct redshift after being covered by BSA. It have been demonstrated that BSA-coated small gold nanorods exhibit better biocompatibility [48].

\subsection{Ligand Exchange Method}

The ligand exchange method is another commonly used method to remove the CTAB on the surface of the gold nanorods. For this method, thiol-terminated molecules, such as 11-mercaptoundecanoic acid and thiol-terminated polyethylene glycol (SH-PEG) are used to replace the CTAB due to the strong Au-S covalent bond. Several studies $[49,50]$ have demonstrated that 11-mercaptoundecanoic acid can replace the CTAB on the Au nanorods effectively. The thiol of the 11-mercaptoundecanoic acid can bind on the Au nanorods firmly via the Au-S bond, while the carboxyl of the 11-mercaptoundecanoic acid can be used to conjugate with other biomolecules, which is beneficial to the application of gold nanorods in biomedicine fields. However, the low 
water content of the 11-mercaptoundecanoic acid capped gold nanorods limits its wide usage in bio-applications. Due to the ability of PEG to prevent undesired protein adhesion while at the same time being nontoxic and having good water solubility [51], the thiol-terminated polyethylene glycol (SH-PEG) with functional group $\left(-\mathrm{NH}_{2}\right.$ or $\left.-\mathrm{COOH}\right)$ has been widely used in the surface modification of gold nanorods. As shown in Figure 4, the CTAB can be removed completely once the SH-PEG is added to the CTAB-capped gold nanorods solution via ligand exchange. Several reports have demonstrated that the PEG-capped gold nanorods can improve biocompatibility effectively and they have been used as imaging and photothermal therapy agents [18,52].

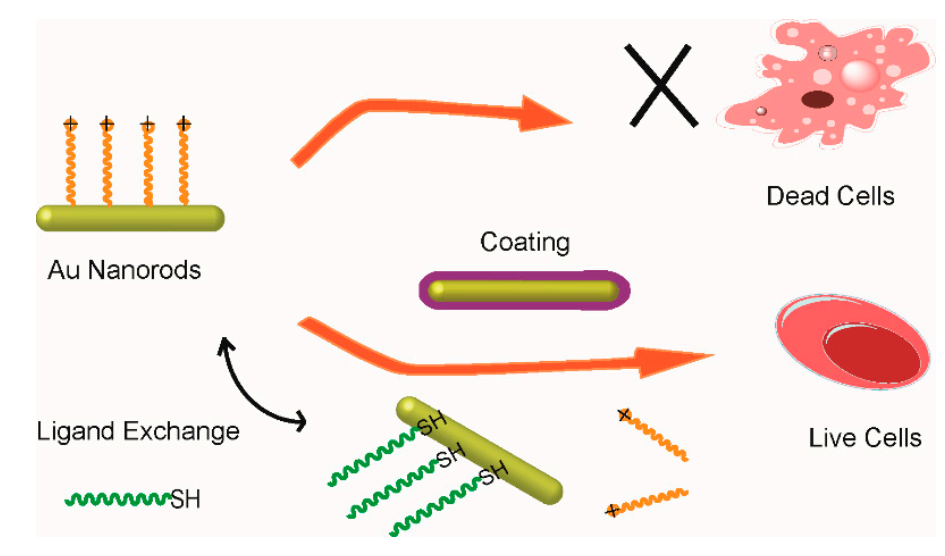

Figure 4. Schematic illustration of the surface modification of small gold nanorods by surface coating and ligand exchange methods.

\section{Biological Imaging}

In the field of non-invasive diagnostic and therapeutic fields for cancer, real-time imaging of cancer is a goal that people have been pursuing [53-55]. Fluorescence imaging as a pure optical imaging technology has been widely used for cancer detection [56-58]. Even though the sensitivity of fluorescence imaging is very high, most of the fluorescence sensor is based on ultra-violet-visible (UV-VIS) light [59] and the low penetration depth limits their applications in vivo. Therefore, it is necessary to find a high-contrast and high-resolution non-destructive medical imaging method.

\subsection{Photoacoustic Imaging}

Photoacoustic tomography (PAT), which is based on the NIR laser, developed quickly recently as a non-destructive medical imaging method [60-62], which combines the high contrast characteristics of optical imaging and the high penetration depth characteristics of ultrasound imaging [63-65]. Photoacoustic (PA) imaging agents that show strong NIR absorption can effectively improve the contrast and also be investigated widely by the researchers [62]. Among all of the photoacoustic agents including organic dyes [66], semiconductors [67,68], and noble metal materials [69,70], gold nanorods are the most widely used as the NIR absorption can be precisely regulated by adjusting the aspect ratio.

Pini et al. [71] investigate the influence of size on the photostability and reproducibility of photoacoustic conversion of gold nanorods embedded in biomimetic phantoms. They tested photostability of different sized Au nanorods by acquiring the PA response at the level of single laser shots (Figure 5). PA signals with good signal-to-noise ratios were recorded from all samples at fluences below the maximal permissible exposure limits. Within this test, Au nanorods suffered from partial reshaping and sublimation or fragmentation, which changed their plasmon bands and limited their value as a PA contrast agent. However, there is an interesting phenomenon in that smaller nanoparticles provides better stable signals and have tolerate higher fluencies (Figure 5B). These results provide new inspiration and indications for small Au nanorods for specific PA applications in biomedical imaging. Subsequently, Song et al. [31] developed a small gold nanorods (AuNR) vesicles 
( $\approx 60 \mathrm{~nm}$ in size) coated with polyethylene glycol (PEG) and poly(lactic-co-glycolic acid) (PLGA) as a PA imaging agents. In comparison with the PEGylated AuNR, the mice treated with the same amount of the AuNR@PEG/PLGA vesicles showed a much stronger PA signal in the tumor region at the same time points, suggesting higher uptake of the AuNR@PEG/PLGA vesicles in the tumor region.
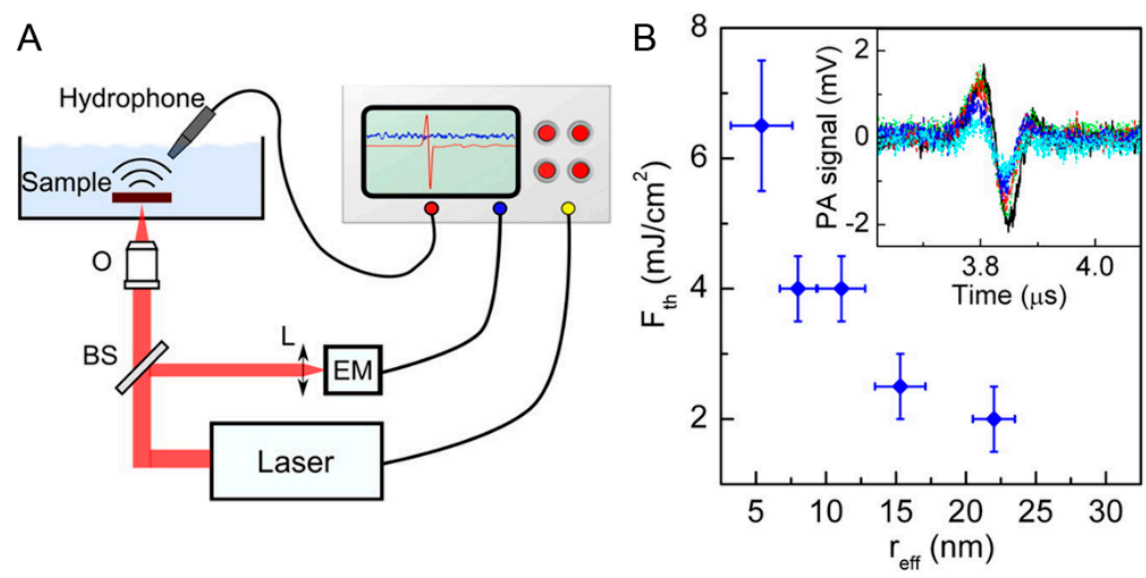

Figure 5. (A) Sketch of the setup used for the photoacoustic experiments $(\mathrm{O}$, objective; $\mathrm{L}$, focusing lens; BS, beam splitter; EM, energy meter); (B) trend of $F_{\text {th }}$ as a function of effective nanoparticle radius $\left(\mathrm{r}_{\mathrm{eff}}\right)$. In the inset: comparison of PA response with a single pulse excitation at fluence $F<F_{\text {th }}$ for samples containing gold nanorod (GNR)5 (black line), GNR8 (green line), GNR11 (red line), GNR15 (dark blue line), and GNR22 (light blue line). GNR5, GNR8, GNR11, GNR15, and GNR22, with the numbers denoting their average effective radii (radius of a sphere having the same volume as the rod) in nanometers [71].

\subsection{Two-Color Photothermal Imaging Microscopy}

Photothermal imaging (PhI) microscopy technology displays extremely stable signals and has unprecedented sensitivities for detecting tiny absorbers with an absorption cross-section as small as a few $10^{-16} \mathrm{~cm}^{2}$ [72-74]. Several types of nanoparticles including gold nanoparticles, carbon nanotubes, and quantum dots $[75,76]$ have been studied for ultrasensitive photothermal imaging applications. However, these nanoparticles have to be excited at their plasmon resonance at around $530 \mathrm{~nm}$ which is similar with background signal from endogenous cellular components. The use of gold nanorods as small probes absorbing in the near infrared is a promising strategy for single-particle level detection, as they would combine good subcellular accessibility, low contribution from intrinsic cellular signals, and perfect photostability [77]. Concerning this, Lounis et al. [78] developed a new strategy for photothermal imaging based on small gold nanorods. Photothermal imaging microscopy (Figure 6A) is constructed with a two-color excitation beam and a near infrared probe beam that can resonate the nanorods in its transverse or longitudinal plasma resonance. Due to the strong optical absorption tunable from the red to the near infrared, the use of small gold nanorods based on this imaging technology can minimize background signals from the cell organelles. As shown in the Figure 6B, the cellular (mitochondrial) structures are clearly visible under $532 \mathrm{~nm}$ excitation (Figure 6B(b)), which complicates the identification of nanorods around the mitochondria at this excitation wavelength. By contrast, background signals originating from mitochondria are notably reduced under $640 \mathrm{~nm}$ excitation (Figure 6B). In addition, individual nanorods display notably higher PhI signals under $640 \mathrm{~nm}$ excitation compared with $532 \mathrm{~nm}$ excitation, facilitating their detection in cellular environments. This small gold nanorod-based photothermal imaging microscopy technology will constitute next generation photothermal probes for studying complex molecular dynamics in biological systems owing to their small size, tunable NIR-absorption, absolute photostability, and chemical suitability for surface functionalization and bioconjugation. 


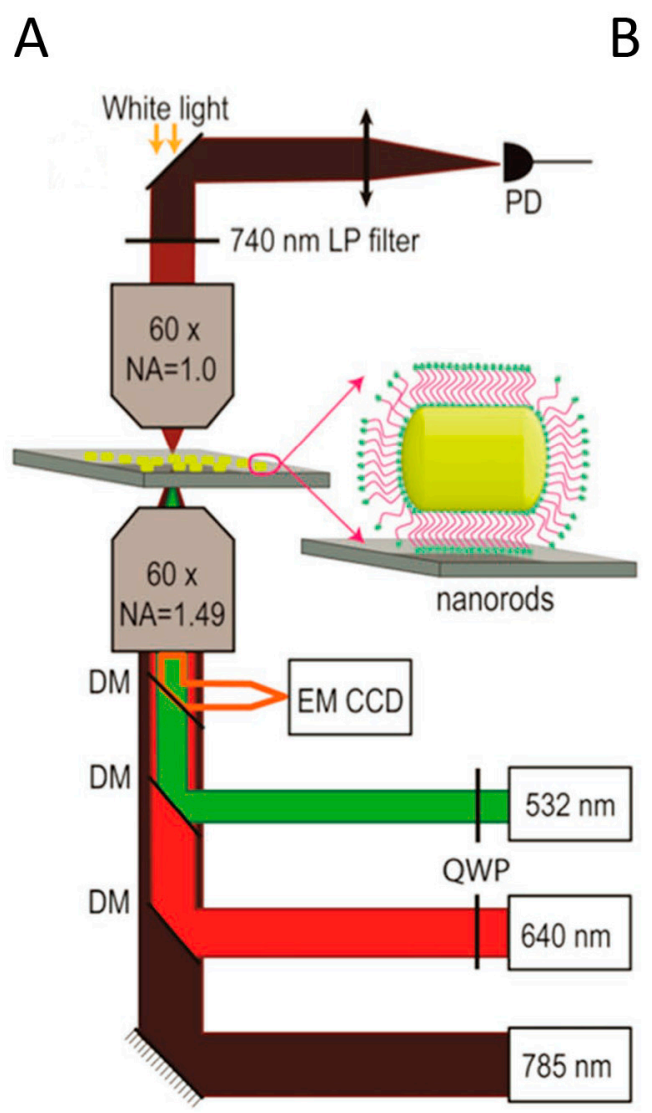

B

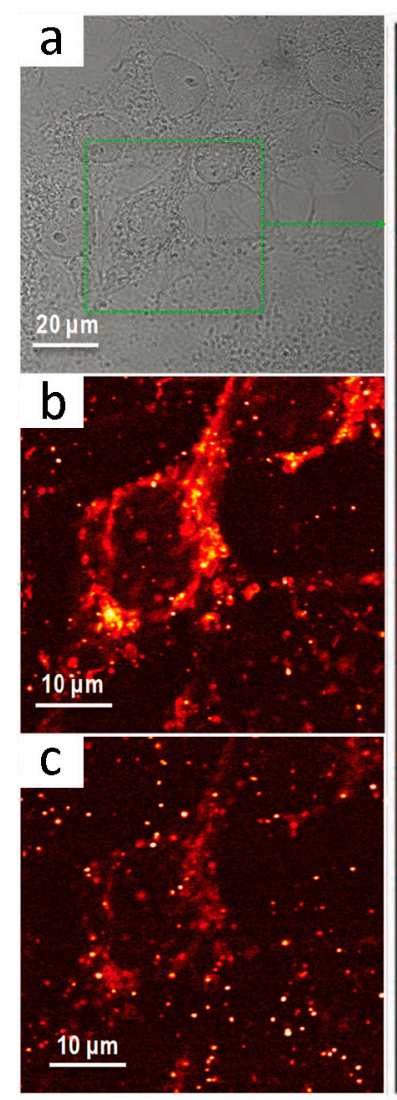

0.2

0.1

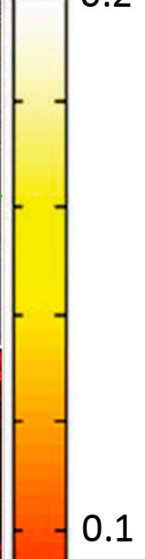

0.0

Figure 6. (A) Schematics of the two-color photothermal imaging microscopy with a near infrared probe beam at $785 \mathrm{~nm}$ and excitations beam at 532 or $640 \mathrm{~nm}$; (B) White light (a) and PhI images of COS 7 cells incubated with nanorods under (b) 532 and (c) $640 \mathrm{~nm}$ excitation. Photothermal imaging microscopy recorded under red excitation shows very weak mitochondrial background signals compared to those acquired under green excitation [78].

\subsection{NIR-Absorbing Imaging}

NIR light (700-1000 nm) for NIR optical imaging [79] can penetrate several centimeters into tissue, because hemoglobin and water, the primary absorbers of visible and infrared light, experience their lowest absorptions in the NIR region. Thus, NIR-absorbing imaging could offer a potentially non-invasive and real-time characterization method for disease using NIR imaging probes [80]. Among the reported NIR imaging probes, including quantum dots, fluorescent dye-doped nanoparticles, etc., gold nanorods are a potential direct NIR absorption imaging probe because the main absorption band is located in the NIR region due to longitudinal surface plasmon. Haam et al. [81] functionalized the Au nanorods with cyclic Arg-Gly-Asp peptides (cRGD). Figure 7 shows the selective NIR-absorbing imaging using cRGD-conjugated PEGylated GNRs (PGNRs). After intravenously injecting with the cRGD-conjugated PGNRs and cRAD-conjugated PGNRs into mice with orthotopic glioma xenografts $(n=4)$, the mice were imaged by NIR absorption imaging for $12 \mathrm{~h}$. Consequently, specific targeting of cRGD-PGNRs to the tumor region was observed via a significant increase in the absorption signal (high absorbance, blue color) that was maintained for $12 \mathrm{~h}$. However, when control cRAD-PGNRs were injected into the tumor-bearing mouse model, the absorption at the tumor site did not change for $12 \mathrm{~h}$. This method is more efficient and simple to determine the localized surface plasmon resonances (LSPR) absorption intensity in molecular imaging. 

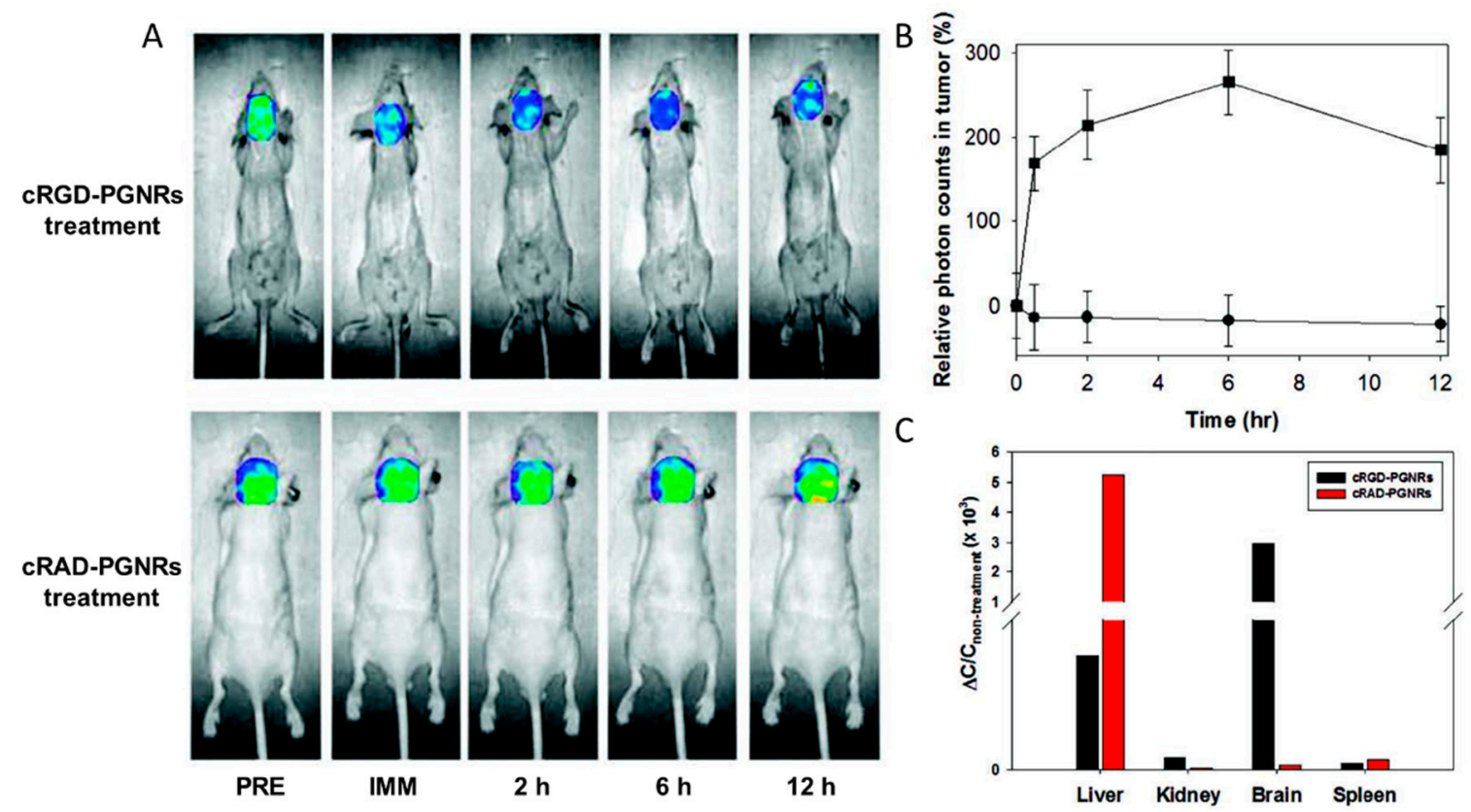

Figure 7. In vivo non-invasive near-infrared (NIR) absorption images of real-time tumor specificity of cRGD-PGNRs. (A) In vivo time-dependent brain region biodistribution of cRGD-PGNRs and cRAD-PGNRs as a control; (B) relative photon counts of in vivo tumor target specificity of cRGD-PGNRs (square) and cRAD-PGNRs (circle) was recorded; and (C) relative quantification of in vivo biodistribution of cRGD-PGNRs and cRAD-PGNRs in different tissues [81].

\section{Cancer Therapy}

\subsection{Photothermal Therapy}

NIR laser-driven photothermal therapy, which converts NIR laser energy to heat energy, has attracted much interest due to its minimally invasive and potentially effective results compared with the conventional approaches, such as surgery, radiation therapy, chemotherapy, hormone therapy, immunotherapy, etc. [3,82]. In order to promote the photothermal conversion efficiency and particularly improve laser discrimination for targeted cancers, the photothermal agents are generally indispensable [83-85]. Among various photothermal therapy agents, the strong absorption properties of the gold nanorods from the visible region to the near-infrared region allows light energy to be efficiently converted to thermal energy under near-infrared laser irradiation, making it possible to perform laser-selective heating at a local range [52,86]. Moreover, the gold nanorods with diameters smaller than $10 \mathrm{~nm}$ are dominated by absorption, which could minimize the impact of the scattering cross-section [30,33]. Thus, the small gold nanorod-assisted laser thermal method has great applications in bio-imaging and cancer therapy, which can selectively destroy cancer cells and not damage benign cells [87,88].

Utilizing the prepared absorption-dominant small gold nanorods, Jia et al. [38] compared their photothermal performance with larger-sized gold nanorods. The cellular uptake efficiencies of the two nanorods samples in three cell lines (U-87 MG, MDA-MB-231, and MDA-MB-435S cells) were evaluated by inductively coupled plasma optical emission spectrometer (ICP-OES) in comparison to addition of the same concentration of $\mathrm{Au}$. They found the internalized number of large $\mathrm{Au}$ nanorods was much larger than that of small nanorods in U-87 MG lines. However, both samples showed similar cellular uptake abilities in MDA-MB-231 and MDA-MB-435S cell lines (Figure 8A). These results indicate that both the particle size and cell type influence the cellular uptake of gold nanorods. Subsequently, the photothermal performance was performed on three different cell lines under the irradiation of $809 \mathrm{~nm}$ laser with a power density of $12 \mathrm{~W} \cdot \mathrm{cm}^{-2}$ for $3 \mathrm{~min}$, then evaluated and compared by 3-(4,5-dimethylthiazol-2-yl)-2,5-diphenyltetrazolium bromide (MTT) 
assay (Figure 8B). The photothermal therapy (PTT) efficiency per unit amount of the internalized Au nanorods was defined as the cell viability reduction divided by the intracellular Au content in each cell line. Compared with the values of $0.95,1.7$, and 1.2\% per pg of Au in U-87 MG, MDA-MB-231, and MDA-MB-435S cells of large gold nanorods, the absorption-dominant small gold nanorods exhibit much higher values $(1.7 \%, 3.0 \%$, and $2.4 \%)$. These results demonstrate that the small Au nanorods show a higher photothermal therapeutic efficacy on these cancer cells than the large Au nanorods at the same internalized Au amount, and suggest that the absorption-dominant small Au nanorods are promising for plasmonic photothermal conversion-based biomedical applications.

A

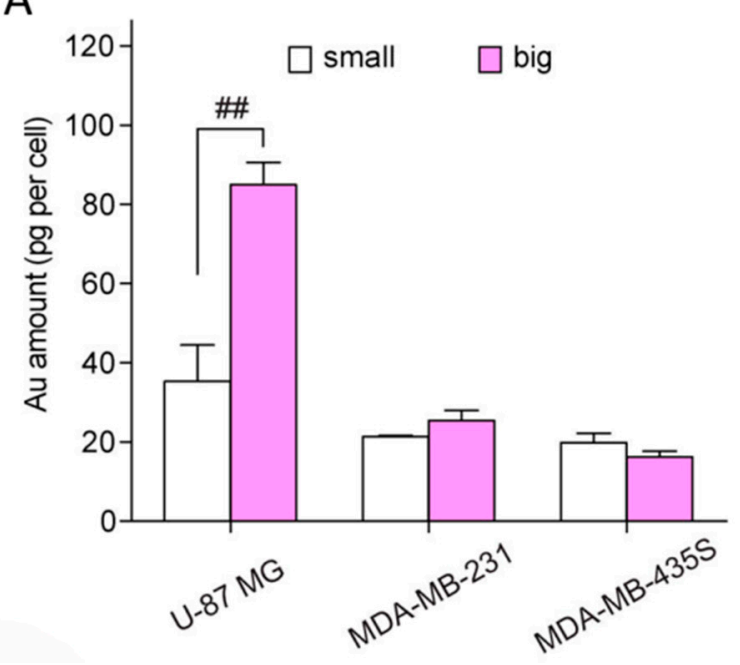

B

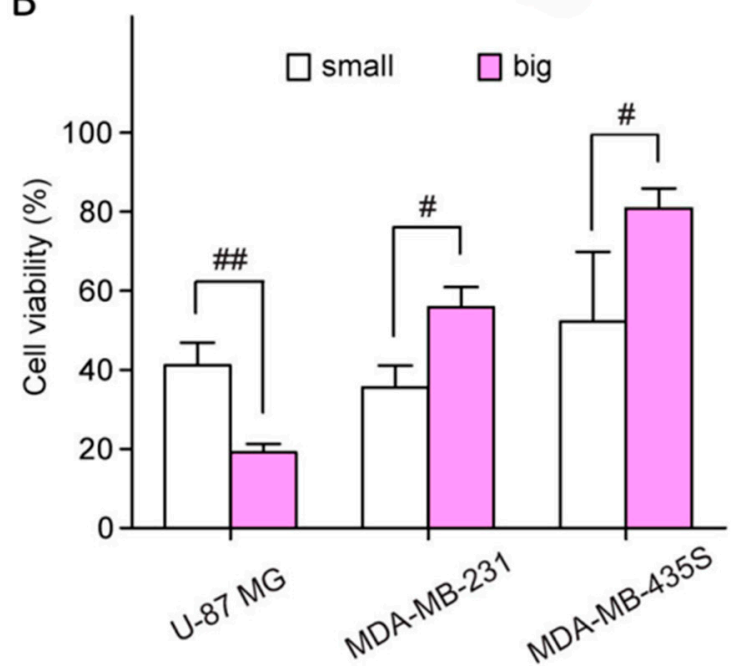

Figure 8. (A) Intracellular $\mathrm{Au}$ contents of the small (white) and large (pink) silica-coated Au nanorods samples in U-87 MG, MDA-MB-231, and MDA-MB-435S cells; and (B) cell viability upon photothermal therapy with small (white) and large (pink) silica-coated Au nanorod samples in U-87 MG, MDA-MB-231, and MDAMB-435S cells [38].

El-Sayed et al. [86] synthesized the small gold nanorods (average size: $\sim 25 \mathrm{~nm} \times 6 \mathrm{~nm}$ ) functionalized with methoxy polyethylene glycol thiol (mPEG-SH), Arg-Gly-Asp (RGD) peptides and nuclear localization signal (NLS) peptides. The uptake of gold nanorods was observed through dark-field (DF) microscopy (Figure 9A). Human oral squamous cell carcinoma (HSC-3) cells were incubated with AuNRs of $2.5 \mathrm{~nm}$ for $24 \mathrm{~h}$. Compared with pure cells and cells incubated AuNRs without NLS, clearly internalization was observed by DF microscopy for cells exposed to AuNRs-NLS. The effect of plasmonic photothermal therapy (PPTT) was confirmed by cell viability assays and apoptosis/necrosis assays (Figure 9B,C). A $808 \mathrm{~nm}$ NIR laser with power of $5.8 \mathrm{~W} / \mathrm{cm}^{2}$ was used to irradiate the cells at different times. Compared with cells without laser irradiation, and cells only incubated with AuNRs-NLS, the AuNRs-NLS with laser groups has an obvious effect of PPTT after exposure to the laser for $3 \mathrm{~min}$. The percentage of viability for the HSC cells incubated with AuNRs-NLS after laser irradiation decreased to $60 \%$, and the number of apoptotic cells also increased. These results indicated that the AuNRs-NLS can accurately target the nucleus and enhance plasmonic photothermal therapy. 
A

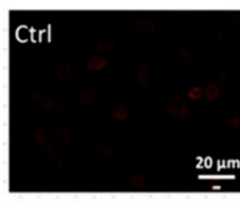

AUNRs@PEG

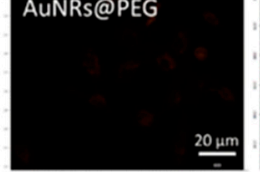

B

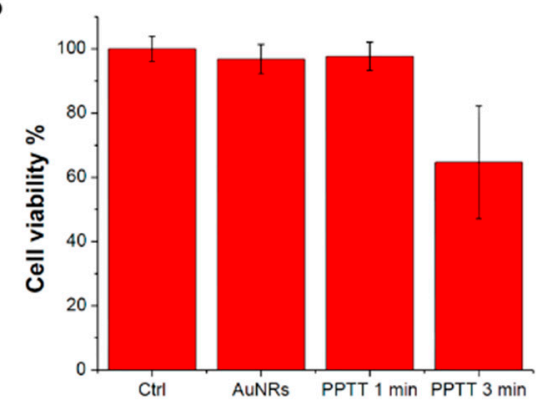

C

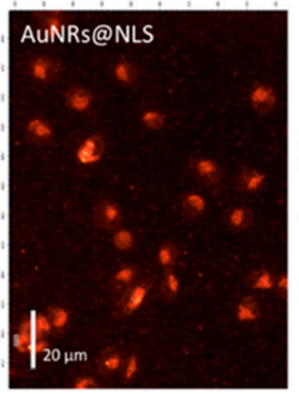

C

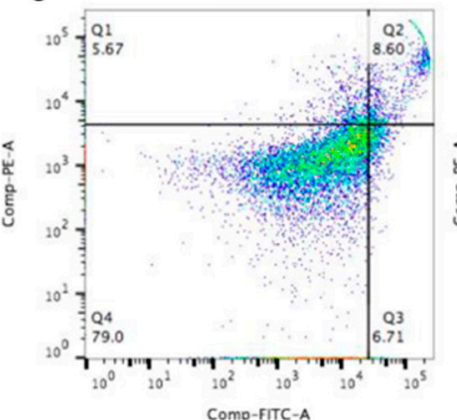

Como-FITC-A

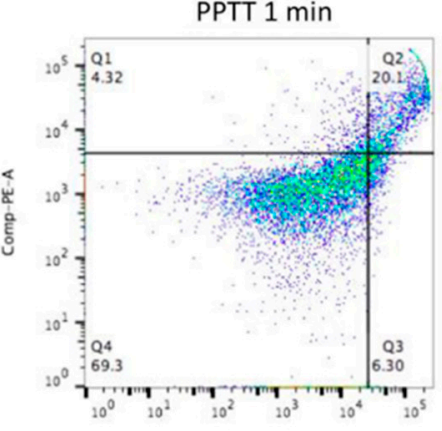

Como-FITC-A
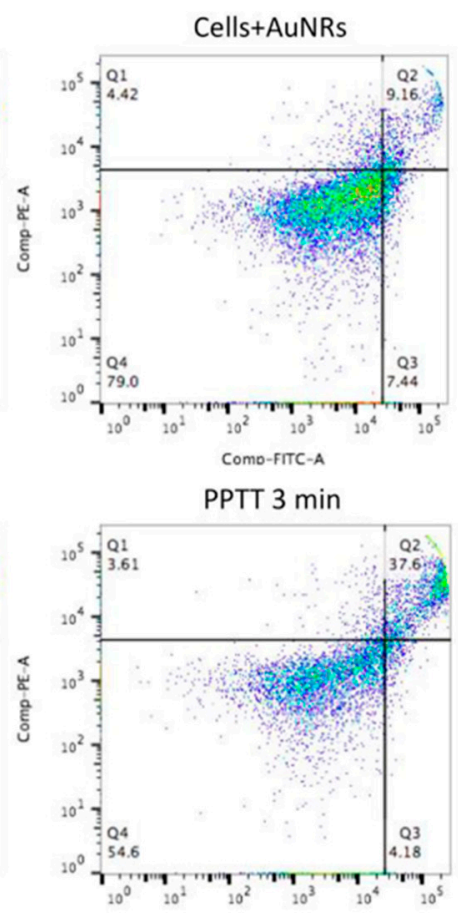

Figure 9. (A) Dark-field images of pure HSC-3 cells, cell incubated AuNRs@PEG, and cells incubated in AuNRs@NLS for $24 \mathrm{~h}$. Scale bar = $20 \mu \mathrm{m}$; cell viability (B) and apoptosis/necrosis assay (C) for the HSC-3 cells treated with PPTT at different times; Q1 (necrosis), Q2 (apoptosis), Q3 (early apoptosis) and Q4 (early apoptosis) [86].

\subsection{Image-Guided Photothermal Therapy}

Recently, theranostic nanomaterials for real-time diagnosis and cancer PTT has been an attractive method for the treatment of solid tumors as it has the advantages of high efficiency, concurrent accurate diagnosis and efficient in situ therapy of tumors [89]. In this regard, absorption-dominant small-sized gold nanorods (GNR) with diameters smaller than $\sim 6 \mathrm{~nm}$ have been investigated for photo-activated cancer therapy. To make the GNR-based PTT visualization, various imaging agents were employed to be integrated with GNRs. However, these imaging-guided therapy patterns still suffer from a low signal to noise ratio [90]. Based on this background, Zhang et al. [28] successfully fabricated an original activatable theranostic agent (AUGNRs) for "off-on" fluorescence imaging guiding PTT (Figure 10). The CTAB-coated ultrasmall GNRs were first placed in cysteamine, and a near-infrared dye (Cy5) conjugated onto the ultrasmall gold nanorods as the fluorescent component. Cy5 was highly quenched by the GNRs in a normal tissue, while being activated in the tumor cells. For the existence of glutathione (GSH), a highly reactive thiol were found in the cytoplasm of tumor cells. GSH can competitively replace the $\mathrm{Cy} 5$ and conjugate with the gold nanorods, and the fluorescence of $\mathrm{Cy} 5 \mathrm{can}$ recover rapidly. The study provided a new strategy for clinical tumor theranostics with image-guided photothermal cancer therapy. 


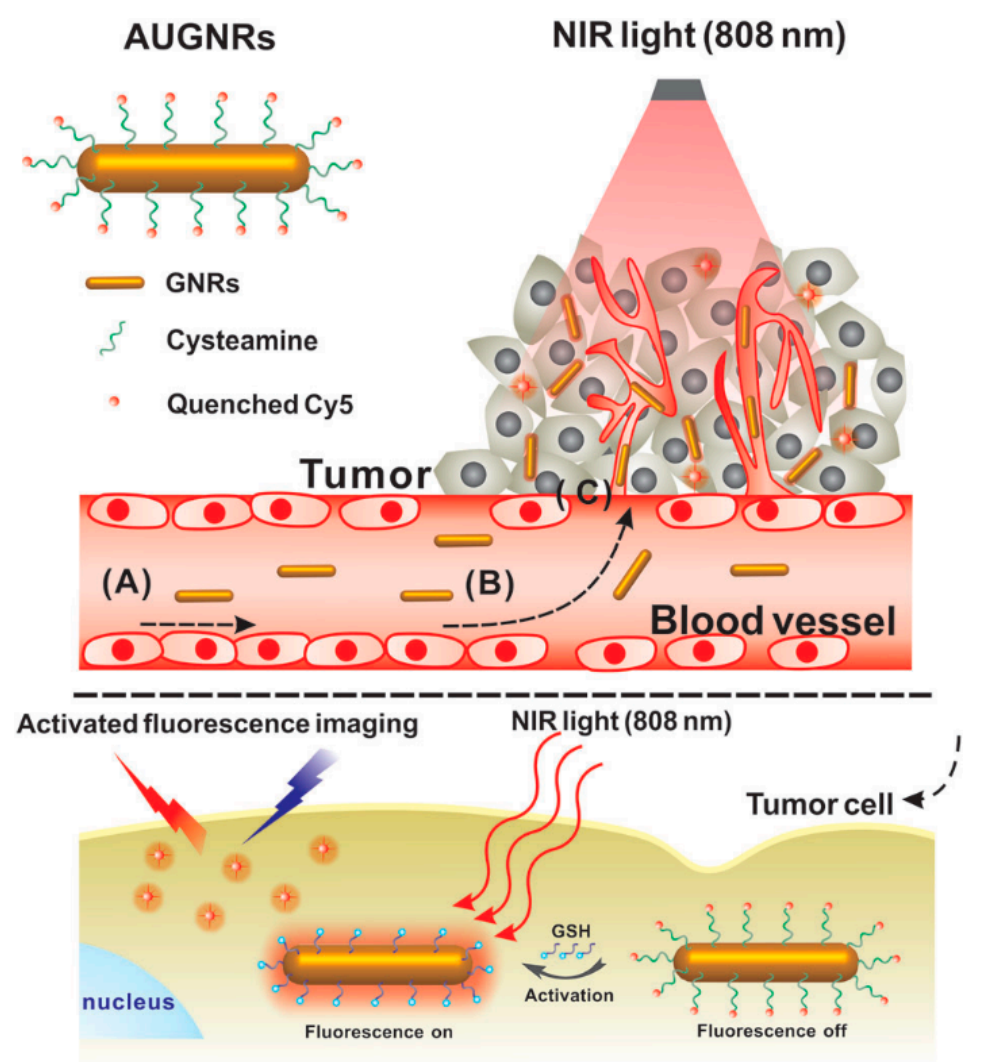

Figure 10. Schematic illustration of the whole procedure for the activatable ultrasmall GNR-based "off-on" fluorescence imaging-guided PTT in tumor cells [28].

Concerning the balance of higher tumor accumulation efficiency and rapid clearance from the body after therapy [91-93], a vesicle assembled by ultra-small gold nanorods was developed by Chen et al. [31] to improve the photothermal therapeutic effect (Figure 11). As shown in Figure 11B, the temperature of the tumor for the mice injected with AuNR@PEG/PLGA vesicles (AuNR Ve) increased up to $20{ }^{\circ} \mathrm{C}$ after $5 \mathrm{~min}$ of irradiation with an $808 \mathrm{~nm}$ laser $\left(0.8 \mathrm{~W} \mathrm{~cm}^{-2}\right)$, which was much higher than the mice treated with AuNR@PEG (AuNR, $\approx 5^{\circ} \mathrm{C}$ temperature increase) and phosphate-buffered saline (PBS) (negligible temperature increase). The higher temperature will induce irreversible tissue damage, which is necessary for the photothermal therapy. The tracked curative effect (Figure 11D) further supports this conclusion, as all the tumors were completely ablated and no reoccurrence was observed when treated with AuNR Ve with a $808 \mathrm{~nm}$ laser, compared with the AuNR and laser irradiation group. The tumor sections stained with hematoxylin and eosin for the AuNR Ve plus laser-treated group showed an intensive necrosis area, while highly pleomorphic nuclei and many mitoses, which are the features of the infiltrating tumor cells, was observed for the PBS or laser-only treatment group. Most importantly, most of the vesicles were cleared from the body after ten days post-injection, due to most of the vesicles being disassembled into single polyethylene glycol-modified Au nanorods as triggered by the hydrolysis of PLGA, which is very essential and beneficial for meeting the requirements of the US Food and Drug Administration [94]. These results suggest that the newly-developed ultra-small gold nanorod vesicles provide opportunities for further clinical translation. 
A
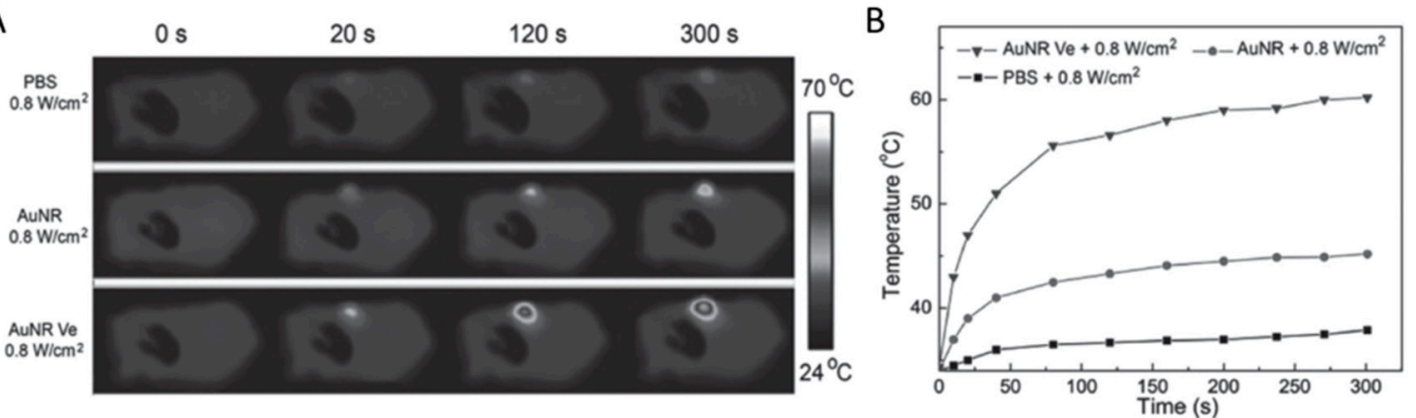

$\mathrm{C}$
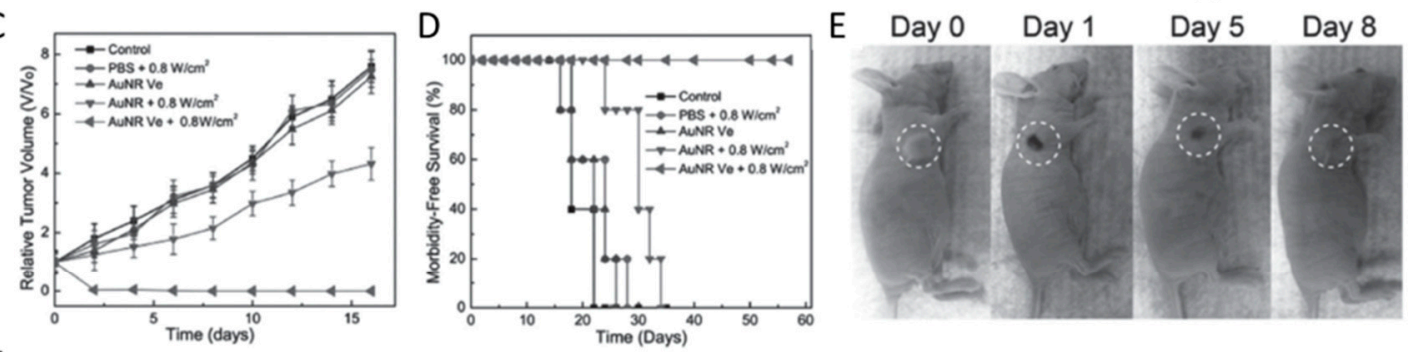

$\mathrm{F}$
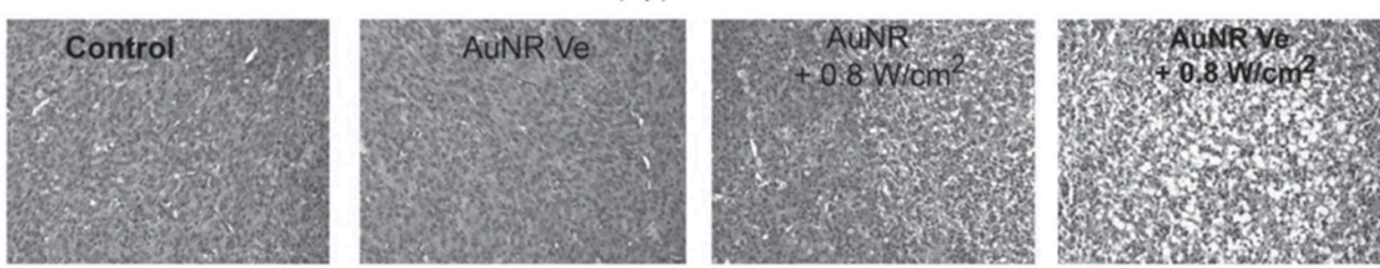

Figure 11. In vivo photothermal ablation of tumor after intravenous injection of Au nanorod vesicles followed by laser irradiation. (A) Infrared thermographic maps and (B) temperature changes of the tumor region treated with small AuNRs and AuNR Ve and irradiated with a $808 \mathrm{~nm}$ laser at different power densities; (C) tumor growth curves and (D) survival curves of tumor-bearing mice treated with phosphate-buffered saline (PBS), small AuNRs and AuNR Ve and laser irradiation; (E) photographs of the tumor-bearing mice at days $0,1,5$, and $8 \mathrm{~d}$ after being treated with the AuNR Ve; and (F) hematoxylin and eosin (H\&E) staining of the tumor tissue after different treatments [31].

\subsection{Cell-Mediated Photothermal Therapy}

In order to overcome the drawback that the injected nanoparticles cannot penetrate the tumor mass, leading to incomplete ablation and disease recurrence [95], the cell-mediated delivery of nanoparticles, which can cross the nearly-impermeable biological barriers to reach many areas in the body [96-98], was developed to improve agent delivery in vivo and enhance photothermal agent efficiency. Based on this, the macrophage delivery system was used by Chu et al. [99] to transport $7 \mathrm{~nm}$ diameter Au nanorods for cancer therapy (Figure 12). They first investigated macrophage uptake, which is important for photothermal conversion. Compared with the commonly used $14 \mathrm{~nm}$ diameter gold nanorods, the small gold nanorods showed much higher macrophage uptake and negligible cytotoxicity due to their small size. Then, the photothermal therapeutic effect was studied by intratumoral injection of $50 \mu \mathrm{L}$ of PBS (control), free small gold nanorods (105 $\mu \mathrm{g} \mathrm{Au}$ ) dispersed in $50 \mu \mathrm{L}$ of PBS, or small gold nanorod-laden macrophages (105 $\mu \mathrm{g}$ Au in $~ 1 \times 10^{6}$ RAW264.7 macrophages) dispersed in $50 \mu \mathrm{L}$ of PBS. The macrophages could deliver small gold nanorods to the entire tumor after intratumoral injection, resulting in photothermal conversion being greatly improved almost everywhere in the tumor, with tumor recurrence rates minimized compared to free BSA-coated small gold nanorods. Their findings not only provided an effective approach to improving photothermal therapy efficiency by delivering the agents to whole tumors, but also expedited the clinical application of nanotechnology for cancer treatment. 
A
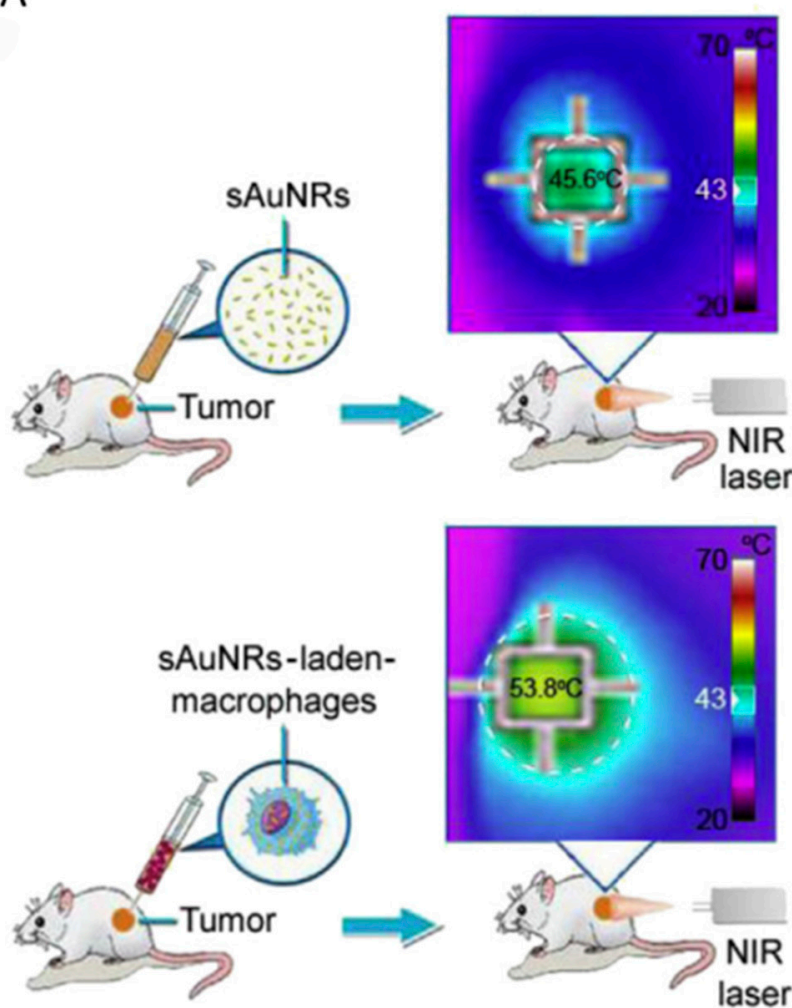

\section{B}
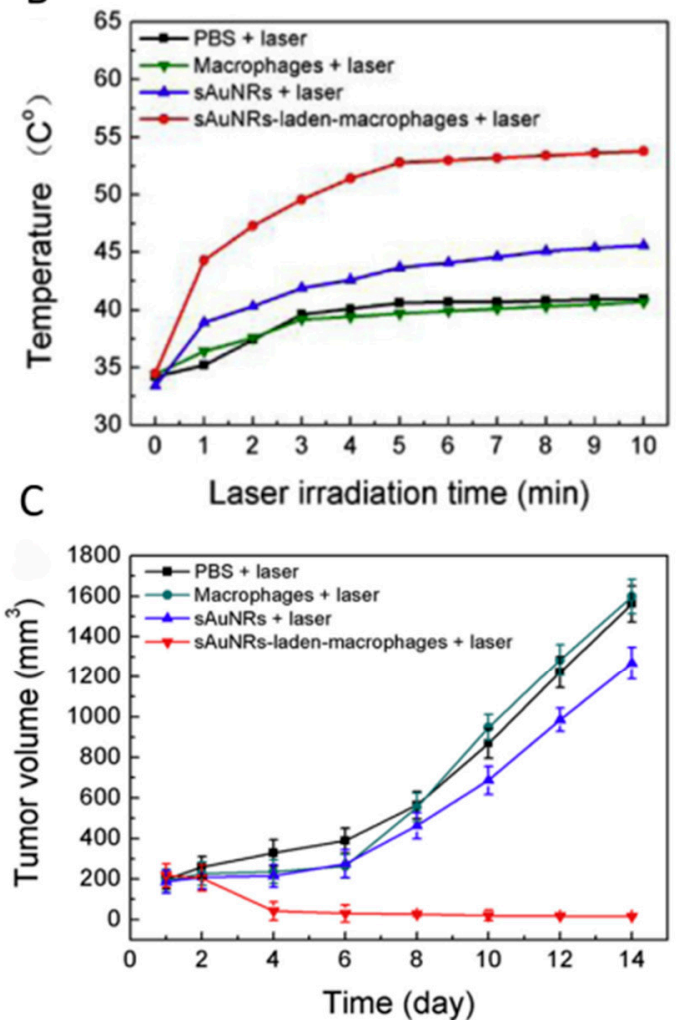

Figure 12. (A) Diagram highlighting the difference between the treatment of free small gold nanorods and macrophage-loaded small gold nanorods; (B) temperature profile of tumor under $808 \mathrm{~nm}$ light irradiation for $10 \mathrm{~min}$; and (C) growth of tumors in the different groups of mice after the irradiation treatments [99].

\subsection{Photothermal-Chemo Combination Therapy}

Reduced graphene oxide (rGO) nanoparticles with a large surface area for drug loading and photothermal effects for photothermal therapy have been widely explored for theranostic applications [100]. Although rGO can absorb light from the UV to NIR and subsequently release it as heat by nonradioactive decay, the broad absorption spectrum and low quantum efficiency of rGO means that it has relatively low photothermal conversion efficiency [101]. rGO-conjugated doxorubicin (DOX) also led to potential toxicity while circulating in a physiological environment. In a recent study, a new kind of carbon-metal hybrid rGO-conjugated DOX (rGO-DOX)-loaded ultrasmall plasmonic gold nanorod vesicle (rGO-AuNRVe-DOX) (Figure 13) for integrated chemo-photothermal therapy was successfully fabricated by Chen et al. [102]. The gold nanorod vesicle was prepared by assembling amphiphilic small gold nanorods $(\sim 9 \mathrm{~nm} \times 2 \mathrm{~nm})$ grafted with poly-(ethylene glycol) (PEG) and poly(lactic-co-glycolic acid) (PLGA). The nanorod vesicle can avoid rGO-DOX to interact with normal tissue and also enhance the photothermal effect. Additionally, the inside of a plasmonic metal shell can behave as a cavity where electromagnetic radiation is concentrated, leading to increased light absorption efficiency of the encapsulated rGO [103]. Furthermore, the nanovesicles will break and release the rGO-DOX and DOX from the vesicle, improving cancer therapy efficacy. 


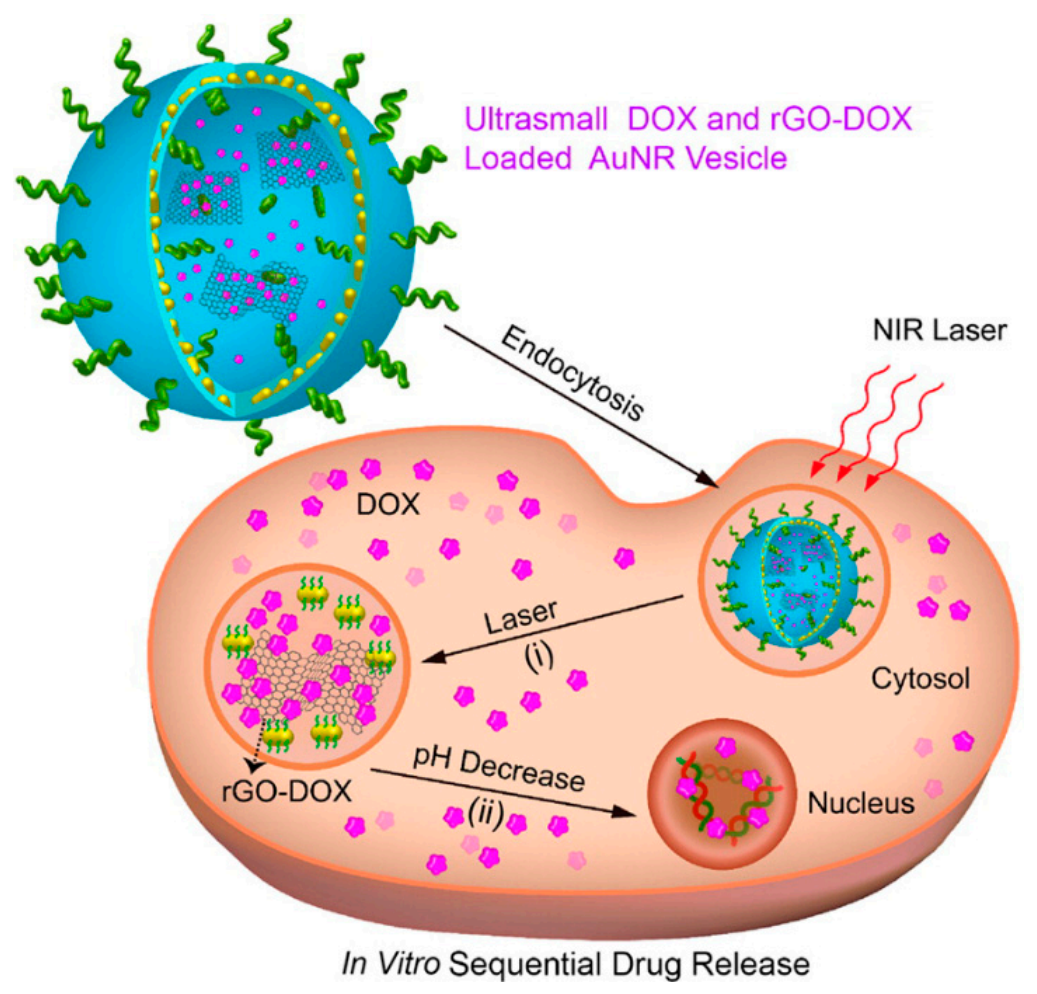

Figure 13. Schematic illustration of sequential DOX release triggered by (i) remote NIR laser irradiated photothermal effect and (ii) acidic environment of the cancer cell [102].

\section{Cytotoxicity and Metabolizable Ability of Small Gold Nanorods}

The safety profile of gold nanorods remains largely undefined. Generally speaking, it is considered biocompatible. Several studies $[104,105]$ have indicated no significant short-term toxicity of gold nanoparticles over three months. However, there are also some other studies [106] that have reported that the presence of gold nanoparticles causes cytotoxicity or inflammation in mouse livers [104]. Particularly, gold nanorods may cause cytotoxicity if they are not completely purified of surfactant CTAB. Additionally, the ideal agents in diagnosis and therapy should be completely cleared from the human body within a reasonable period. Therefore, it is essential to understand the organ uptake, biodistribution, longer-term fate, and toxicity of AuNRs, and to provide a strong framework for their clinic translation. El-Sayed et al. [88] studied the 15-month toxicity and fate of small gold nanorods in a mouse model. The histopathology of tissues from the liver, spleen, lung, and kidney of mice was evaluated by a pathologist at one month and 15 months after single intravenous injection of AuNR@PEG. There were no histopathological abnormalities in any of the mouse organs. AuNRs@PEG remained inside the cells without any structure over a long period, from visual observation of the organ tissue microstructure. During the whole treatment, gold nanorods accumulated in mouse organs without any evidence of toxicities. Similarly, Yu et al. [34] studied the size of gold nanorod impact on cytotoxicity from in vivo biodistribution. Compared to the large-sized gold nanorods (bAuNRs), the small-sized gold nanorods (sAuNRs) were cleared much more rapidly than bAuNRs (Figure 14). Therefore, small-sized gold nanorods are more suitable for in vivo imaging and tumor therapy. 

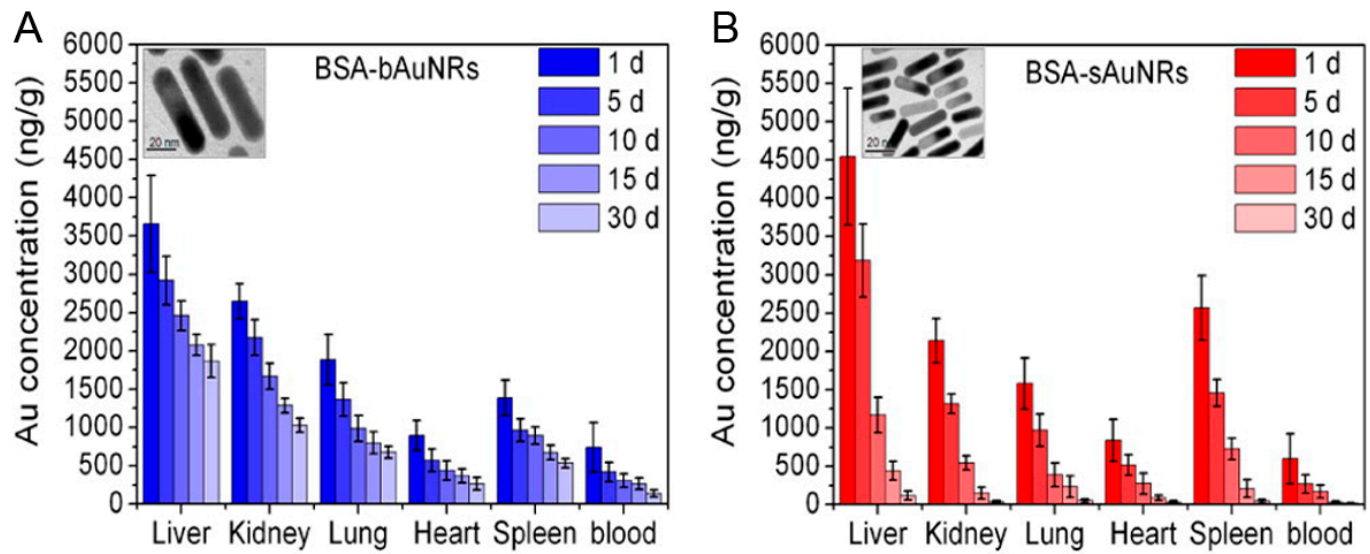

Figure 14. In vivo biodistribution and clearance of (A) BSA-bAuNRs and (B) BSA-sAuNRs together with $\mathrm{Au}$ concentrations at the different time points of $1,5,10,15$, and 30 days after intravenous injection (5 mg Au/kg). The inset are typical TEM images of the bAuNRs and sAuNRs, respectively [34].

\section{Future Challenges and Prospects}

The unique surface plasma optical properties and their ultra-small size make ultra-small gold nanorods able to be widely used in the bio-imaging and cancer treatment. At the same time, ultra-small gold nanorod synthesis, surface modification, and functional applications have also made great progress. However, two aspects still need to be further improved: first, the yield of ultra-small gold nanorods needs to be improved, which may require further understanding of the process of growth of gold nanorods in solution; and, second, the extinction coefficient, which is related with the photothermal conversion efficiency, of small gold nanorods prepared by the seedless method is smaller than those prepared using the seeded technique. Thus, it is necessary to develop new methods to modify the small gold nanorods, thus, obtaining higher extinction coefficients and subsequently higher photothermal conversion efficiencies, which is of benefit to cancer treatment. With the advancement of modern science and technology, greater drawbacks for small gold nanorods will be overcome. We believe that the clinical application of small gold nanorods will be achieved in the future.

Acknowledgments: This work was partially supported by National Natural Science Foundation of China (Nos. 21601124 and 21671135), Program of Young Eastern Scholar from Shanghai Institutions of Higher Learning (QD2015038), Shanghai Rising-Star Program (17QA1402600), the Natural Science Foundation of Shanghai (16ZR1424700), Ministry of Education of China (PCSIRT_IRT_16R49), and International Joint Laboratory on Resource Chemistry (IJLRC).

Conflicts of Interest: The authors declare no conflict of interest.

\section{References}

1. Gao, Z.; Hou, Y.; Zeng, J.; Chen, L.; Liu, C.; Yang, W.; Gao, M. Tumor microenvironment-triggered aggregation of antiphagocytosis ${ }^{99 \mathrm{~m}} \mathrm{Tc}$-labeled $\mathrm{Fe}_{3} \mathrm{O}_{4}$ nanoprobes for enhanced tumor imaging in vivo. Adv. Mater. 2017, 1701095. [CrossRef] [PubMed]

2. Yu, X.; Li, A.; Zhao, C.; Yang, K.; Chen, X.; Li, W. Ultrasmall semimetal nanoparticles of bismuth for dual-modal computed tomography/photoacoustic imaging and synergistic thermoradiotherapy. ACS Nano 2017, 11, 3990-4001. [CrossRef] [PubMed]

3. Cheng, L.; Wang, C.; Feng, L.; Yang, K.; Liu, Z. Functional nanomaterials for phototherapies of cancer. Chem. Rev. 2014, 114, 10869-10939. [CrossRef] [PubMed]

4. Liu, Z.; Cai, W.; He, L.; Nakayama, N.; Chen, K.; Sun, X.; Chen, X.; Dai, H. In vivo biodistribution and highly efficient tumour targeting of carbon nanotubes in mice. Nat. Nano 2007, 2, 47-52. [CrossRef] [PubMed]

5. Chaplin, A.B.; Hooper, J.F.; Weller, A.S.; Willis, M.C. Intermolecular hydroacylation: High activity rhodium catalysts containing small-bite-angle diphosphine ligands. J. Am. Chem. Soc. 2012, 134, 4885-4897. [CrossRef] [PubMed] 
6. Yang, K.; Zhang, S.; Zhang, G.; Sun, X.; Lee, S.-T.; Liu, Z. Graphene in mice: Ultrahigh in vivo tumor uptake and efficient photothermal therapy. Nano Lett. 2010, 10, 3318-3323. [CrossRef] [PubMed]

7. Tian, Q.; Tang, M.; Sun, Y.; Zou, R.; Chen, Z.; Zhu, M.; Yang, S.; Wang, J.; Wang, J.; Hu, J. Hydrophilic flower-like CuS superstructures as an efficient $980 \mathrm{~nm}$ laser-driven photothermal agent for ablation of cancer cells. Adv. Mater. 2011, 23, 3542-3547. [CrossRef] [PubMed]

8. Chen, Z.; Wang, Q.; Wang, H.; Zhang, L.; Song, G.; Song, L.; Hu, J.; Wang, H.; Liu, J.; Zhu, M.; et al. Ultrathin PEGylated $\mathrm{W}_{18} \mathrm{O}_{49}$ nanowires as a new $980 \mathrm{~nm}$-laser-driven photothermal agent for efficient ablation of cancer cells in vivo. Adv. Mater. 2013, 25, 2095-2100. [CrossRef] [PubMed]

9. Wang, Y.; Wu, Y.; Liu, Y.; Shen, J.; Lv, L.; Li, L.; Yang, L.; Zeng, J.; Wang, Y.; Zhang, L.W.; et al. BSA-mediated synthesis of bismuth sulfide nanotheranostic agents for tumor multimodal imaging and thermoradiotherapy. Adv. Funct. Mater. 2016, 26, 5335-5344. [CrossRef]

10. Cheng, X.; Sun, R.; Yin, L.; Chai, Z.; Shi, H.; Gao, M. Light-triggered assembly of gold nanoparticles for photothermal therapy and photoacoustic imaging of tumors in vivo. Adv. Mater. 2017, 29, 1604894. [CrossRef] [PubMed]

11. Xing, R.; Liu, K.; Jiao, T.; Zhang, N.; Ma, K.; Zhang, R.; Zou, Q.; Ma, G.; Yan, X. An injectable self-assembling collagen-gold hybrid hydrogel for combinatorial antitumor photothermal/photodynamic therapy. Adv. Mater. 2016, 28, 3669-3676. [CrossRef] [PubMed]

12. Chen, J.; Wang, D.; Xi, J.; Au, L.; Siekkinen, A.; Warsen, A.; Li, Z.-Y.; Zhang, H.; Xia, Y.; Li, X. Immuno gold nanocages with tailored optical properties for targeted photothermal destruction of cancer cells. Nano Lett. 2007, 7, 1318-1322. [CrossRef] [PubMed]

13. Danan, Y.; Yariv, I.; Zalevsky, Z.; Sinvani, M. Improved margins detection of regions enriched with gold nanoparticles inside biological phantom. Materials 2017, 10, 203. [CrossRef] [PubMed]

14. Li, X.; Xing, L.; Zheng, K.; Wei, P.; Du, L.; Shen, M.; Shi, X. Formation of gold nanostar-coated hollow mesoporous silica for tumor multimodality imaging and photothermal therapy. ACS Appl. Mater. Interfaces 2017, 9, 5817-5827. [CrossRef] [PubMed]

15. Dickerson, E.B.; Dreaden, E.C.; Huang, X.; El-Sayed, I.H.; Chu, H.; Pushpanketh, S.; McDonald, J.F.; El-Sayed, M.A. Gold nanorod assisted near-infrared plasmonic photothermal therapy (PPTT) of squamous cell carcinoma in mice. Cancer Lett. 2008, 269, 57-66. [CrossRef] [PubMed]

16. Kang, X.; Guo, X.; Niu, X.; An, W.; Li, S.; Liu, Z.; Yang, Y.; Wang, N.; Jiang, Q.; Yan, C.; et al. Photothermal therapeutic application of gold nanorods-porphyrin-trastuzumab complexes in HER2-positive breast cancer. Sci. Rep. 2017, 7, 42069. [CrossRef] [PubMed]

17. Lee, C.; Hwang, H.S.; Lee, S.; Kim, B.; Kim, J.O.; Oh, K.T.; Lee, E.S.; Choi, H.-G.; Youn, Y.S. Rabies virus-inspired silica-coated gold nanorods as a photothermal therapeutic platform for treating brain tumors. Adv. Mater. 2017, 29, 1605563. [CrossRef] [PubMed]

18. Mackey, M.A.; Ali, M.R.K.; Austin, L.A.; Near, R.D.; El-Sayed, M.A. The most effective gold nanorod size for plasmonic photothermal therapy: Theory and in vitro experiments. J. Phys. Chem. B 2014, 118, 1319-1326. [CrossRef] [PubMed]

19. Yang, X.; Yang, M.; Pang, B.; Vara, M.; Xia, Y. Gold nanomaterials at work in biomedicine. Chem. Rev. 2015, 115, 10410-10488. [CrossRef] [PubMed]

20. Burrows, N.D.; Harvey, S.; Idesis, F.A.; Murphy, C.J. Understanding the seed-mediated growth of gold nanorods through a fractional factorial design of experiments. Langmuir 2017, 33, 1891-1907. [CrossRef] [PubMed]

21. Zhang, L.; Xia, K.; Lu, Z.; Li, G.; Chen, J.; Deng, Y.; Li, S.; Zhou, F.; He, N. Efficient and facile synthesis of gold nanorods with finely tunable plasmonic peaks from visible to near-IR range. Chem. Mater. 2014, 26, 1794-1798. [CrossRef]

22. Weissleder, R. A clearer vision for in vivo imaging. Nat. Biotechnol. 2001, 19, 316-317. [CrossRef] [PubMed]

23. Zhou, W.; Gao, X.; Liu, D.; Chen, X. Gold nanoparticles for in vitro diagnostics. Chem. Rev. 2015, 115, 10575-10636. [CrossRef] [PubMed]

24. Liu, X.; Huang, N.; Li, H.; Wang, H.; Jin, Q.; Ji, J. Multidentate polyethylene glycol modified gold nanorods for in vivo near-infrared photothermal cancer therapy. ACS Appl. Mater. Interfaces 2014, 6, 5657-5668. [CrossRef] [PubMed]

25. Yasun, E.; Li, C.; Barut, I.; Janvier, D.; Qiu, L.; Cui, C.; Tan, W. BSA modification to reduce CTAB induced nonspecificity and cytotoxicity of aptamer-conjugated gold nanorods. Nanoscale 2015, 7, 10240-10248. [CrossRef] [PubMed] 
26. Riley, R.S.; Day, E.S. Gold nanoparticle-mediated photothermal therapy: Applications and opportunities for multimodal cancer treatment. Wiley Interdiscip. Rev. Nanomed. Nanobiotechnol. 2017, 9, e1449. [CrossRef] [PubMed]

27. Zhang, Z.; Wang, J.; Nie, X.; Wen, T.; Ji, Y.; Wu, X.; Zhao, Y.; Chen, C. Near infrared laser-induced targeted cancer therapy using thermoresponsive polymer encapsulated gold nanorods. J. Am. Chem. Soc. 2014, 136, 7317-7326. [CrossRef] [PubMed]

28. Zhao, F.; Li, X.; Li, J.; Dou, Y.; Wang, L.; Wu, M.; Liu, Y.; Chang, J.; Zhang, X. Activatable ultrasmall gold nanorods for "off-on" fluorescence imaging-guided photothermal therapy. J. Mater. Chem. B 2017, 5, 2145-2151. [CrossRef]

29. Huang, X.; El-Sayed, I.H.; Qian, W.; El-Sayed, M.A. Cancer cell imaging and photothermal therapy in the near-infrared region by using gold nanorods. J. Am. Chem. Soc. 2006, 128, 2115-2120. [CrossRef] [PubMed]

30. Chen, H.; Shao, L.; Ming, T.; Sun, Z.; Zhao, C.; Yang, B.; Wang, J. Understanding the photothermal conversion efficiency of gold nanocrystals. Small 2010, 6, 2272-2280. [CrossRef] [PubMed]

31. Song, J.; Yang, X.; Jacobson, O.; Huang, P.; Sun, X.; Lin, L.; Yan, X.; Niu, G.; Ma, Q.; Chen, X. Ultrasmall gold nanorod vesicles with enhanced tumor accumulation and fast excretion from the body for cancer therapy. Adv. Mater. 2015, 27, 4910-4917. [CrossRef] [PubMed]

32. Yu, M.; Zheng, J. Clearance pathways and tumor targeting of imaging nanoparticles. ACS Nano 2015, 9, 6655-6674. [CrossRef] [PubMed]

33. Ni, W.; Kou, X.; Yang, Z.; Wang, J. Tailoring longitudinal surface plasmon wavelengths, scattering and absorption cross sections of gold nanorods. ACS Nano 2008, 2, 677-686. [CrossRef] [PubMed]

34. Li, Z.; Tang, S.; Wang, B.; Li, Y.; Huang, H.; Wang, H.; Li, P.; Li, C.; Chu, P.K.; Yu, X.-F. Metabolizable small gold nanorods: Size-dependent cytotoxicity, cell Uptake and in vivo viodistribution. ACS Biomater. Sci. Eng. 2016, 2, 789-797. [CrossRef]

35. Liu, J.; Yu, M.; Zhou, C.; Zheng, J. Renal clearable inorganic nanoparticles: A new frontier of bionanotechnology. Mater. Today 2013, 16, 477-486. [CrossRef]

36. Jana, N.R.; Gearheart, L.; Murphy, C.J. Seed-mediated growth approach for shape-controlled synthesis of spheroidal and rod-like gold nanoparticles using a surfactant template. Adv. Mater. 2001, 13, 1389-1393. [CrossRef]

37. Ali, M.R.; Snyder, B.; El-Sayed, M.A. Synthesis and optical properties of small Au nanorods using a seedless growth technique. Langmuir 2012, 28, 9807-9815. [CrossRef] [PubMed]

38. Jia, H.; Fang, C.; Zhu, X.M.; Ruan, Q.; Wang, Y.X.; Wang, J. Synthesis of absorption-dominant small gold nanorods and their plasmonic properties. Langmuir 2015, 31, 7418-7426. [CrossRef] [PubMed]

39. Nikoobakht, B.; El-Sayed, M.A. Preparation and growth mechanism of gold nanorods (NRs) using seed-mediated growth method. Chem. Mater. 2003, 15, 1957-1962. [CrossRef]

40. Lohse, S.E.; Eller, J.R.; Sivapalan, S.T.; Plews, M.R.; Murphy, C.J. A simple millifluidic benchtop reactor system for the high-throughput synthesis and functionalization of gold nanoparticles with different sizes and shapes. ACS Nano 2013, 7, 4135-4150. [CrossRef] [PubMed]

41. Sau, T.K.; Murphy, C.J. Seeded high yield synthesis of short Au nanorods in aqueous solution. Langmuir 2004, 20, 6414-6420. [CrossRef] [PubMed]

42. Jana, N.R. Gram-scale synthesis of soluble, near-monodisperse gold nanorods and other anisotropic nanoparticles. Small 2005, 1, 875-882. [CrossRef] [PubMed]

43. Samal, A.K.; Sreeprasad, T.S.; Pradeep, T. Investigation of the role of $\mathrm{NaBH}_{4}$ in the chemical synthesis of gold nanorods. J. Nanopart. Res. 2009, 12, 1777-1786. [CrossRef]

44. Zijlstra, P.; Bullen, C.; Chon, J.W.M.; Gu, M. High-temperature seedless synthesis of gold nanorods. J. Phys. Chem. B 2006, 110, 19315-19318. [CrossRef] [PubMed]

45. Pérez-Juste, J.; Liz-Marzán, L.M.; Carnie, S.; Chan, D.Y.C.; Mulvaney, P. Electric-field-directed growth of gold nanorods in aqueous surfactant solutions. Adv. Funct. Mater. 2004, 14, 571-579. [CrossRef]

46. Alkilany, A.M.; Nagaria, P.K.; Hexel, C.R.; Shaw, T.J.; Murphy, C.J.; Wyatt, M.D. Cellular Uptake and Cytotoxicity of Gold Nanorods: Molecular Origin of Cytotoxicity and Surface Effects. Small 2009, 5, 701-708. [CrossRef] [PubMed]

47. Luo, G.-F.; Chen, W.-H.; Lei, Q.; Qiu, W.-X.; Liu, Y.-X.; Cheng, Y.-J.; Zhang, X.-Z. A Triple-Collaborative Strategy for High-Performance Tumor Therapy by Multifunctional Mesoporous Silica-Coated Gold Nanorods. Adv. Funct. Mater. 2016, 26, 4339-4350. [CrossRef] 
48. Ali, M.R.K.; Panikkanvalappil, S.R.; El-Sayed, M.A. Enhancing the efficiency of gold nanoparticles treatment of cancer by increasing their rate of endocytosis and cell accumulation using rifampicin. J. Am. Chem. Soc. 2014, 136, 4464-4467. [CrossRef] [PubMed]

49. Wijaya, A.; Hamad-Schifferli, K. Ligand customization and DNA functionalization of gold nanorods via round-trip phase transfer ligand exchange. Langmuir 2008, 24, 9966-9969. [CrossRef] [PubMed]

50. Yu, C.; Varghese, L.; Irudayaraj, J. Surface modification of cetyltrimethylammonium bromide-capped gold nanorods to make molecular probes. Langmuir 2007, 23, 9114-9119. [CrossRef] [PubMed]

51. Boyer, J.-C.; Manseau, M.-P.; Murray, J.I.; van Veggel, F.C.J.M. Surface Modification of Upconverting NaYF4 Nanoparticles with PEG-Phosphate Ligands for NIR $(800 \mathrm{~nm})$ Biolabeling within the Biological Window. Langmuir 2010, 26, 1157-1164. [CrossRef] [PubMed]

52. Ali, M.R.; Ibrahim, I.M.; Ali, H.R.; Selim, S.A.; El-Sayed, M.A. Treatment of natural mammary gland tumors in canines and felines using gold nanorods-assisted plasmonic photothermal therapy to induce tumor apoptosis. Int. J. Nanomed. 2016, 11, 4849-4863. [CrossRef]

53. Smith, B.R.; Gambhir, S.S. Nanomaterials for in vivo imaging. Chem. Rev. 2017, 117, 901-986. [CrossRef] [PubMed]

54. Tirotta, I.; Mastropietro, A.; Cordiglieri, C.; Gazzera, L.; Baggi, F.; Baselli, G.; Bruzzone, M.G.; Zucca, I.; Cavallo, G.; Terraneo, G.; et al. A superfluorinated molecular probe for highly sensitive in vivo ${ }^{19} \mathrm{~F}-\mathrm{MRI}$. J. Am. Chem. Soc. 2014, 136, 8524-8527. [CrossRef] [PubMed]

55. Chen, J.; Ratnayaka, S.; Alford, A.; Kozlovskaya, V.; Liu, F.; Xue, B.; Hoyt, K.; Kharlampieva, E. Theranostic multilayer capsules for ultrasound imaging and guided drug delivery. ACS Nano 2017, 11, 3135-3146. [CrossRef] [PubMed]

56. Dong, H.; Du, S.-R.; Zheng, X.-Y.; Lyu, G.-M.; Sun, L.-D.; Li, L.-D.; Zhang, P.-Z.; Zhang, C.; Yan, C.-H. Lanthanide nanoparticles: From design toward bioimaging and therapy. Chem. Rev. 2015, 115, 10725-10815. [CrossRef] [PubMed]

57. Yin, C.; Zhen, X.; Zhao, H.; Tang, Y.; Ji, Y.; Lyu, Y.; Fan, Q.; Huang, W.; Pu, K. Amphiphilic semiconducting oligomer for near-infrared photoacoustic and fluorescence imaging. ACS Appl. Mater. Interfaces 2017, 9, 12332-12339. [CrossRef] [PubMed]

58. Nair, L.V.; Nazeer, S.S.; Jayasree, R.S.; Ajayaghosh, A. Fluorescence imaging assisted photodynamic therapy using photosensitizer-linked gold quantum clusters. ACS Nano 2015, 9, 5825-5832. [CrossRef] [PubMed]

59. Ezeh, V.C.; Harrop, T.C. A sensitive and selective fluorescence sensor for the detection of arsenic(III) in organic media. Inorg. Chem. 2012, 51, 1213-1215. [CrossRef] [PubMed]

60. Ai, X.; Ho, C.J.H.; Aw, J.; Attia, A.B.E.; Mu, J.; Wang, Y.; Wang, X.; Wang, Y.; Liu, X.; Chen, H.; et al. In vivo covalent cross-linking of photon-converted rare-earth nanostructures for tumour localization and theranostics. Nat. Commun. 2016, 7, 10432. [CrossRef] [PubMed]

61. Shi, B.; Gu, X.; Fei, Q.; Zhao, C. Photoacoustic probes for real-time tracking of endogenous $\mathrm{H}_{2} \mathrm{~S}$ in living mice. Chem. Sci. 2017, 8, 2150-2155. [CrossRef] [PubMed]

62. Pu, K.; Shuhendler, A.J.; Jokerst, J.V.; Mei, J.; Gambhir, S.S.; Bao, Z.; Rao, J. Semiconducting polymer nanoparticles as photoacoustic molecular imaging probes in living mice. Nat. Nano 2014, 9, 233-239. [CrossRef] [PubMed]

63. Kruger, R.A.; Liu, P. Photoacoustic ultrasound: Pulse production and detection in 0.5\% Liposyn. Med. Phys. 1994, 21, 1179-1184. [CrossRef] [PubMed]

64. Suzuki, K.; Yamashita, Y.; Ohta, K.; Kaneko, M.; Yoshida, M.; Chance, B. Quantitative measurement of optical parameters in normal breasts using time-resolved spectroscopy: In vivo results of 30 Japanese women. J. Biomed Opt. 1996, 1, 330-334. [CrossRef] [PubMed]

65. Yao, Y.; Xing, D.; He, Y.; Ueda, K.-I. Acousto-optic tomography using amplitude-modulated focused ultrasound and a near-IR laser. Quantum Electron. 2001, 31, 1023-1026. [CrossRef]

66. Sheng, Z.; Hu, D.; Zheng, M.; Zhao, P.; Liu, H.; Gao, D.; Gong, P.; Gao, G.; Zhang, P.; Ma, Y.; et al. Smart human serum albumin-indocyanine green nanoparticles generated by programmed assembly for dual-modal imaging-guided cancer synergistic phototherapy. ACS Nano 2014, 8, 12310-12322. [CrossRef] [PubMed]

67. Cheng, L.; Liu, J.; Gu, X.; Gong, H.; Shi, X.; Liu, T.; Wang, C.; Wang, X.; Liu, G.; Xing, H.; et al. PEGylated $\mathrm{WS}_{2}$ nanosheets as a multifunctional theranostic agent for in vivo dual-modal $\mathrm{CT} /$ photoacoustic imaging guided photothermal therapy. Adv. Mater. 2014, 26, 1886-1893. [CrossRef] [PubMed] 
68. Song, X.-R.; Wang, X.; Yu, S.-X.; Cao, J.; Li, S.-H.; Li, J.; Liu, G.; Yang, H.-H.; Chen, X. CogSe 8 nanoplates as a new theranostic platform for photoacoustic/magnetic resonance dual-modal-imaging-guided chemo-photothermal combination therapy. Adv. Mater. 2015, 27, 3285-3291. [CrossRef] [PubMed]

69. Huang, P.; Rong, P.; Lin, J.; Li, W.; Yan, X.; Zhang, M.G.; Nie, L.; Niu, G.; Lu, J.; Wang, W.; et al. Triphase interface synthesis of plasmonic gold bellflowers as near-infrared light mediated acoustic and thermal theranostics. J. Am. Chem. Soc. 2014, 136, 8307-8313. [CrossRef] [PubMed]

70. Zhang, Y.S.; Wang, Y.; Wang, L.; Wang, Y.; Cai, X.; Zhang, C.; Wang, L.V.; Xia, Y. Labeling human mesenchymal stem cells with gold nanocages for in vitro and in vivo tracking by two-photon microscopy and photoacoustic microscopy. Theranostics 2013, 3, 532-543. [CrossRef] [PubMed]

71. Cavigli, L.; de Angelis, M.; Ratto, F.; Matteini, P.; Rossi, F.; Centi, S.; Fusi, F.; Pini, R. Size affects the stability of the photoacoustic conversion of gold nanorods. J. Phys. Chem. C 2014, 118, 16140-16146. [CrossRef]

72. Boyer, D.; Tamarat, P.; Maali, A.; Lounis, B.; Orrit, M. Photothermal imaging of nanometer-sized metal particles among scatterers. Science 2002, 297, 1160-1163. [CrossRef] [PubMed]

73. Gaiduk, A.; Yorulmaz, M.; Ruijgrok, P.V.; Orrit, M. Room-temperature detection of a single molecule's absorption by photothermal contrast. Science 2010, 330, 353-356. [CrossRef] [PubMed]

74. Tardin, C.; Cognet, L.; Bats, C.; Lounis, B.; Choquet, D. Direct imaging of lateral movements of AMPA receptors inside synapses. EMBO J. 2003, 22, 4656-4665. [CrossRef] [PubMed]

75. Olson, J.; Dominguez-Medina, S.; Hoggard, A.; Wang, L.-Y.; Chang, W.-S.; Link, S. Optical characterization of single plasmonic nanoparticles. Chem. Soc. Rev. 2015, 44, 40-57. [CrossRef] [PubMed]

76. Zijlstra, P.; Paulo, P.M.R.; Orrit, M. Optical detection of single non-absorbing molecules using the surface plasmon resonance of a gold nanorod. Nat. Nano 2012, 7, 379-382. [CrossRef] [PubMed]

77. Leduc, C.; Si, S.; Gautier, J.; Soto-Ribeiro, M.; Wehrle-Haller, B.; Gautreau, A.; Giannone, G.; Cognet, L.; Lounis, B. A highly specific gold nanoprobe for live-cell single-molecule imaging. Nano Lett. 2013, 13, 1489-1494. [CrossRef] [PubMed]

78. Shibu, E.S.; Varkentina, N.; Cognet, L.; Lounis, B. Small gold nanorods with tunable absorption for photothermal microscopy in cells. Adv. Sci. 2017, 4, 1600280. [CrossRef] [PubMed]

79. Zhu, J.; Gong, T.; Kopwitthaya, A.; Hu, R.; Law, W.-C.; Roy, I.; Huang, H.; Yong, K.-T. Synthesis of PEGylated gold nanorods (Au NRs) as absorption nanoprobes for near-infrared optical imaging. RSC Adv. 2013, 3, 12280. [CrossRef]

80. Choi, J.; Yang, J.; Bang, D.; Park, J.; Suh, J.-S.; Huh, Y.-M.; Haam, S. Targetable gold nanorods for epithelial cancer therapy guided by near-IR absorption imaging. Small 2012, 8, 746-753. [CrossRef] [PubMed]

81. Choi, J.; Yang, J.; Park, J.; Kim, E.; Suh, J.-S.; Huh, Y.-M.; Haam, S. Specific near-IR absorption imaging of glioblastomas using integrin-targeting gold nanorods. Adv. Funct. Mater. 2011, 21, 1082-1088. [CrossRef]

82. Tian, Q.; Jiang, F.; Zou, R.; Liu, Q.; Chen, Z.; Zhu, M.; Yang, S.; Wang, J.; Wang, J.; Hu, J. Hydrophilic Cu, $\mathrm{S}_{5}$ nanocrystals: A photothermal agent with a $25.7 \%$ heat conversion efficiency for photothermal ablation of cancer cells in vivo. ACS Nano 2011, 5, 9761-9771. [CrossRef] [PubMed]

83. Chou, S.S.; Kaehr, B.; Kim, J.; Foley, B.M.; De, M.; Hopkins, P.E.; Huang, J.; Brinker, C.J.; Dravid, V.P. Chemically exfoliated $\mathrm{MoS}_{2}$ as near-infrared photothermal agents. Angew. Chem. Int. Ed. 2013, 52, 4160-4164. [CrossRef] [PubMed]

84. Xia, Y.; Li, W.; Cobley, C.M.; Chen, J.; Xia, X.; Zhang, Q.; Yang, M.; Cho, E.C.; Brown, P.K. Gold nanocages: From synthesis to theranostic applications. Acc. Chem. Res. 2011, 44, 914-924. [CrossRef] [PubMed]

85. Yang, J.; Choi, J.; Bang, D.; Kim, E.; Lim, E.-K.; Park, H.; Suh, J.-S.; Lee, K.; Yoo, K.-H.; Kim, E.-K.; et al. Convertible organic nanoparticles for near-infrared photothermal ablation of cancer cells. Angew. Chem. Int. Ed. 2011, 50, 441-444. [CrossRef] [PubMed]

86. Ali, M.R.; Wu, Y.; Han, T.; Zang, X.; Xiao, H.; Tang, Y.; Wu, R.; Fernandez, F.M.; El-Sayed, M.A. Simultaneous Time-Dependent Surface-Enhanced Raman Spectroscopy, Metabolomics, and Proteomics Reveal Cancer Cell Death Mechanisms Associated with Gold Nanorod Photothermal Therapy. J. Am. Chem. Soc. 2016, 138, 15434-15442. [CrossRef] [PubMed]

87. Aioub, M.; Panikkanvalappil, S.R.; El-Sayed, M.A. Platinum-coated gold nanorods: Efficient reactive oxygen scavengers that prevent oxidative damage toward healthy, untreated cells during plasmonic photothermal therapy. ACS Nano 2017, 11, 579-586. [CrossRef] [PubMed] 
88. Ali, M.R.K.; Rahman, M.A.; Wu, Y.; Han, T.; Peng, X.; Mackey, M.A.; Wang, D.; Shin, H.J.; Chen, Z.G.; Xiao, H.; et al. Efficacy, long-term toxicity, and mechanistic studies of gold nanorods photothermal therapy of cancer in xenograft mice. Proc. Natl. Acad. Sci. USA 2017, 114, E3110-E3118. [CrossRef] [PubMed]

89. Sugiura, T.; Matsuki, D.; Okajima, J.; Komiya, A.; Mori, S.; Maruyama, S.; Kodama, T. Photothermal therapy of tumors in lymph nodes using gold nanorods and near-infrared laser light with controlled surface cooling. Nano Res. 2015, 8, 3842-3852. [CrossRef]

90. Ren, X.; Chen, H.; Yang, V.; Sun, D. Iron oxide nanoparticle-based theranostics for cancer imaging and therapy. Front Chem. Sci. Eng. 2014, 8, 253-264. [CrossRef]

91. Irvine, D.J. Drug delivery: One nanoparticle, one kill. Nat. Mater. 2011, 10, 342-343. [CrossRef] [PubMed]

92. Shi, J.; Xiao, Z.; Kamaly, N.; Farokhzad, O.C. Self-assembled targeted nanoparticles: Evolution of technologies and bench to bedside translation. Acc. Chem. Res. 2011, 44, 1123-1134. [CrossRef] [PubMed]

93. Tam, J.M.; Tam, J.O.; Murthy, A.; Ingram, D.R.; Ma, L.L.; Travis, K.; Johnston, K.P.; Sokolov, K.V. Controlled assembly of biodegradable plasmonic nanoclusters for near-infrared imaging and therapeutic applications. ACS Nano 2010, 4, 2178-2184. [CrossRef] [PubMed]

94. Hubbell, J.A.; Chilkoti, A. Nanomaterials for drug delivery. Science 2012, 337, 303. [CrossRef] [PubMed]

95. Chithrani, B.D.; Ghazani, A.A.; Chan, W.C.W. Determining the size and shape dependence of gold nanoparticle uptake into mammalian cells. Nano Lett. 2006, 6, 662-668. [CrossRef] [PubMed]

96. Choi, J.; Kim, H.-Y.; Ju, E.J.; Jung, J.; Park, J.; Chung, H.-K.; Lee, J.S.; Lee, J.S.; Park, H.J.; Song, S.Y.; et al. Use of macrophages to deliver therapeutic and imaging contrast agents to tumors. Biomaterials 2012, 33, 4195-4203. [CrossRef] [PubMed]

97. Choi, M.-R.; Stanton-Maxey, K.J.; Stanley, J.K.; Levin, C.S.; Bardhan, R.; Akin, D.; Badve, S.; Sturgis, J.; Robinson, J.P.; Bashir, R.; et al. A cellular trojan horse for delivery of therapeutic nanoparticles into tumors. Nano Lett. 2007, 7, 3759-3765. [CrossRef] [PubMed]

98. Mooney, R.; Roma, L.; Zhao, D.; Van Haute, D.; Garcia, E.; Kim, S.U.; Annala, A.J.; Aboody, K.S.; Berlin, J.M. Neural stem cell-mediated intratumoral delivery of gold nanorods improves photothermal therapy. ACS Nano 2014, 8, 12450-12460. [CrossRef] [PubMed]

99. Li, Z.; Huang, H.; Tang, S.; Li, Y.; Yu, X.-F.; Wang, H.; Li, P.; Sun, Z.; Zhang, H.; Liu, C.; et al. Small gold nanorods laden macrophages for enhanced tumor coverage in photothermal therapy. Biomaterials 2016, 74, 144-154. [CrossRef] [PubMed]

100. Zhang, W.; Guo, Z.; Huang, D.; Liu, Z.; Guo, X.; Zhong, H. Synergistic effect of chemo-photothermal therapy using PEGylated graphene oxide. Biomaterials 2011, 32, 8555-8561. [CrossRef] [PubMed]

101. Zhu, Y.; Murali, S.; Cai, W.; Li, X.; Suk, J.W.; Potts, J.R.; Ruoff, R.S. Graphene-based materials: Graphene and graphene oxide: Synthesis, properties, and applications. Adv. Mater. 2010, 22, 3906-3924. [CrossRef] [PubMed]

102. Song, J.; Yang, X.; Jacobson, O.; Lin, L.; Huang, P.; Niu, G.; Ma, Q.; Chen, X. Sequential drug release and enhanced photothermal and photoacoustic effect of hybrid reduced graphene oxide-loaded ultrasmall gold nanorod vesicles for cancer therapy. ACS Nano 2015, 9, 9199-9209. [CrossRef] [PubMed]

103. Zhang, P.; Guo, Y. Surface-enhanced raman scattering inside metal nanoshells. J. Am. Chem. Soc. 2009, 131, 3808-3809. [CrossRef] [PubMed]

104. Axiak-Bechtel, S.; Upendran, A.; Lattimer, J.C.; Kelsey, J.; Cutler, C.; Selting, K.; Bryan, J.; Henry, C.; Boote, E.; Tate, D.; et al. Gum arabic-coated radioactive gold nanoparticles cause no short-term local or systemic toxicity in the clinically relevant canine model of prostate cancer. Int. J. Nanomed. 2014, 9, 5001-5011. [CrossRef] [PubMed]

105. Connor, E.E.; Mwamuka, J.; Gole, A.; Murphy, C.J.; Wyatt, M.D. Gold nanoparticles are taken up by human cells but do not cause acute cytotoxicity. Small 2005, 1, 325-327. [CrossRef] [PubMed]

106. Pernodet, N.; Fang, X.; Sun, Y.; Bakhtina, A.; Ramakrishnan, A.; Sokolov, J.; Ulman, A.; Rafailovich, M. Adverse effects of citrate/gold nanoparticles on human dermal fibroblasts. Small 2006, 2, 766-773. [CrossRef] [PubMed]

(C) 2017 by the authors. Licensee MDPI, Basel, Switzerland. This article is an open access article distributed under the terms and conditions of the Creative Commons Attribution (CC BY) license (http:/ / creativecommons.org/licenses/by/4.0/). 